\title{
In situ observations of new particle formation in the tropical upper troposphere: the role of clouds and the nucleation mechanism
}

\author{
R. Weigel ${ }^{1}$, S. Borrmann ${ }^{1,2}$, J. Kazil ${ }^{3,4}$, A. Minikin $^{5}$, A. Stohl ${ }^{6}$, J. C. Wilson ${ }^{7}$, J. M. Reeves ${ }^{7}$, D. Kunkel ${ }^{2}$, M. de Reus ${ }^{1}$, \\ W. Frey ${ }^{2}$, E. R. Lovejoy ${ }^{3}$, C. M. Volk ${ }^{8}$, S. Viciani ${ }^{9}$, F. D'Amato ${ }^{9}$, C. Schiller ${ }^{10}$, T. Peter ${ }^{11}$, H. Schlager ${ }^{5}$, F. Cairo ${ }^{12}$, \\ K. S. Law ${ }^{13}$, G. N. Shur ${ }^{14}$, G. V. Belyaev ${ }^{15}$, and J. Curtius ${ }^{1, *}$ \\ ${ }^{1}$ Institut für Physik der Atmosphäre, Johannes Gutenberg-Universität, Mainz, Germany \\ ${ }^{2}$ Abteilung Partikelchemie, Max-Planck-Institut für Chemie, Mainz, Germany \\ ${ }^{3}$ Cooperative Institute for Research in Environmental Sciences (CIRES), University of Colorado, Boulder, Colorado, USA \\ ${ }^{4}$ NOAA Earth System Research Laboratory, Boulder, Colorado, USA \\ ${ }^{5}$ Institut für Physik der Atmosphäre, Deutsches Zentrum für Luft- und Raumfahrt (DLR), Oberpfaffenhofen, Germany \\ ${ }^{6}$ Norwegian Institute for Air Research (NILU), Kjeller, Norway \\ ${ }^{7}$ Department of Engineering, University of Denver, Denver, Colorado, USA \\ ${ }^{8}$ Institut für Atmosphärenphysik, Bergische Universität Wuppertal, Germany \\ ${ }^{9}$ Istituto Nazionale di Ottica, Consiglio Nazionale delle Ricerche, Firenze, Italy \\ ${ }^{10}$ Institut für Energie- und Klimaforschung - Stratosphäre, Forschungszentrum Jülich, Germany \\ ${ }^{11}$ Institute for Atmospheric and Climate Science, Eidgenössische Technische Hochschule (ETH), Zürich, Switzerland \\ ${ }^{12}$ Istituto di Scienze dell'Atmosfera e del Clima ISAC-CNR, Consiglio Nazionale delle Ricerche, Italy \\ ${ }^{13}$ UPMC Univ. Paris 06; Université Versailles St-Quentin; CNRS/INSU, UMR 8190, LATMOS-IPSL, Paris, France \\ ${ }^{14}$ Central Aerological Observatory, Dolgoprudny, Moskow Region, Russia \\ ${ }^{15}$ MDB-Myasishchev Design Bureau, Zhukovsky-5, Moscow Region, Russia \\ *now at: Institut für Atmosphäre und Umwelt, Goethe-Universität, Frankfurt am Main, Germany
}

Received: 8 March 2011 - Published in Atmos. Chem. Phys. Discuss.: 21 March 2011

Revised: 22 September 2011 - Accepted: 22 September 2011 - Published: 29 September 2011

\begin{abstract}
New particle formation (NPF), which generates nucleation mode aerosol, was observed in the tropical Upper Troposphere (UT) and Tropical Tropopause Layer (TTL) by in situ airborne measurements over South America (JanuaryMarch 2005), Australia (November-December 2005), West Africa (August 2006) and Central America (2004-2007). Particularly intense NPF was found at the bottom of the TTL. Measurements with a set of condensation particle counters (CPCs) with different $d_{\mathrm{p} 50}$ (50\% lower size detection efficiency diameter or "cut-off diameter") were conducted on board the M-55 Geophysica in the altitude range of 12.0$20.5 \mathrm{~km}$ and on board the DLR Falcon-20 at up to $11.5 \mathrm{~km}$ altitude. On board the NASA WB-57F size distributions were measured over Central America in the 4 to $1000 \mathrm{~nm}$ diameter range with a system of nucleation mode aerosol spec-
\end{abstract}

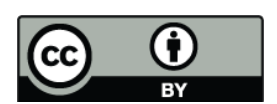

Correspondence to: R. Weigel

(weigelr@uni-mainz.de) trometers. Nucleation mode particle concentrations $\left(N_{\mathrm{NM}}\right)$ were derived from these measurements which allow for identifying many NPF events with $N_{\mathrm{NM}}$ in the range of thousands of particles per $\mathrm{cm}^{3}$. Over Australia and West Africa, we identified NPF in the outflow of tropical convection, in particular of a Mesoscale Convective System (MCS). Newly formed particles with $N_{\mathrm{NM}}>1000 \mathrm{~cm}^{-3}$ were found to coexist with ice cloud particles $\left(d_{\mathrm{p}}>2 \mu \mathrm{m}\right)$ as long as cloud particle concentrations remained below $2 \mathrm{~cm}^{-3}$. The occurrence of NPF within the upper troposphere and the TTL was generally confined within $340 \mathrm{~K}$ to $380 \mathrm{~K}$ potential temperature, but NPF was of particular strength between $350 \mathrm{~K}$ and $370 \mathrm{~K}$ (i.e. $\sim 1-4 \mathrm{~km}$ below the cold point tropopause). Analyses of the aerosol volatility (at $250^{\circ} \mathrm{C}$ ) show that in the TTL on average $75-90 \%$ of the particles were volatile, compared to typically only $50 \%$ in the extra-tropical UT, indicative for the particles to mainly consist of $\mathrm{H}_{2} \mathrm{SO}_{4}-\mathrm{H}_{2} \mathrm{O}$ and possibly organic compounds. Along two flight segments over Central and South America (24 February 2005 and 7 August

Published by Copernicus Publications on behalf of the European Geosciences Union. 
2006, at $12.5 \mathrm{~km}$ altitude) in cloud free air, above thin cirrus, particularly high $N_{\mathrm{NM}}$ were observed. Recent lifting had influenced the probed air masses, and $N_{\mathrm{NM}}$ reached up to 16000 particles $\mathrm{cm}^{-3}$ (ambient concentration). A sensitivity study using an aerosol model, which includes neutral and ion induced nucleation processes, simulates $N_{\mathrm{NM}}$ in reasonable agreement with the in situ observations of clear-air NPF. Based on new, stringent multi-CPC criteria, our measurements corroborate the hypothesis that the tropical UT and the TTL are regions supplying freshly nucleated particles. Our findings narrow the altitude of the main source region to the bottom TTL, i.e. to the level of main tropical convection outflow, and, by means of measurements of carbon monoxide, they indicate the importance of anthropogenic emissions in NPF. After growth and/or coalescence the nucleation mode particles may act as cloud condensation nuclei in the tropical UT, or, upon ascent into the stratosphere, contribute to maintain the stratospheric background aerosol.

\section{Introduction}

Observational evidence suggests that the upper tropical troposphere is one of the most important source regions for the stratospheric particles in the Junge aerosol layer (Brock et al., 1995; Thomason and Peter, 2006; Borrmann et al., 2010). However, an evaluation of the different mechanisms forming new particles by Lucas and Akimoto (2006) revealed that qualitatively, due to the large uncertainties of parameterizations, NPF was so far inadequately represented in global models. Recent studies (Yu et al., 2010; Zhang et al., 2010) suggest that uncertainties in the effectiveness of NPF mechanisms themselves may cause problems in simulating global particle number densities. Nucleation mode aerosol particles form within the UT (Upper Troposphere) and in the TTL (Tropical Transition Layer) altitude region from gaseous precursors, and grow to stable and detectable sizes (e.g. $>3 \mathrm{~nm}$ in diameter $d_{\mathrm{p}}$ ). This process is commonly referred to as "new particle formation" (NPF), or previously as "nucleation event" (because of its sometimes burst-like occurrence). Once formed, the particles are subject to microphysical processes (e.g. coagulation, growth by condensation of water vapor and other gases, evaporation, scavenging). In the tropics, above the level of zero net radiative heating $(Q=0)$ and in the absence of clouds, these aerosols are transported upward into the stratosphere. Strong NPF in burst-like events is thought to occur in the UT/TTL as a consequence of the oxidation of sulfur compounds, possibly aided by the oxidation of organic compounds. The aerosol population and its size distribution in the stratosphere take shape by coagulation, condensation of sulfuric acid and water vapor from the gas phase, and by removal from the stratosphere into the troposphere. Aerosol is removed from the stratosphere by sedimentation or isentropic transport and mixing, e.g. due to tropopause folds (Hamill et al., 1997; Thomason and Peter, 2006) and, with particular efficiency, via the subsiding air masses in the polar winter vortex.

In situ observations of the number concentration of nucleation mode aerosol in the tropical upper troposphere are rare. Brock et al. (1995) identified remnants of recent NPF in tropical upper tropospheric cloud-free air by aircraft-borne in situ detection of high aerosol number concentrations and concurrent high levels of particle volatility. Lee et al. (2003) reported encounters with recent NPF events in $20 \%$ of their samples (i.e. flight segments) between 7 and $20 \mathrm{~km}$ altitude in the tropics. The average number concentration was 1100 particles $\mathrm{cm}^{-3}$ for $4 \mathrm{~nm}<d_{\mathrm{p}}<9 \mathrm{~nm}$. One conclusion from this study was that ion-induced NPF, i.e. a homogeneous nucleation process driven by the abundant presence of ionized air molecules, might have been responsible for some of these NPF events. Lee et al. (2004) also found nucleation events inside subtropical and tropical cirrus clouds between 7 and $16 \mathrm{~km}$ over Florida. Evidence for previous NPF was found in $72 \%$ of their in-cloud samples and in $56 \%$ of the samples outside of clouds. According to Frey et al. (2011) such new particle formation events seem to occur commonly inside anvils and cirrus decks of West African MCS cloud systems. Already Twohy et al. (2002) suggested that mid-latitude MCS play a particular role as a source of new particles in the UT based on in situ detection of elevated aerosol numbers $\left(d_{\mathrm{p}}>25 \mathrm{~nm}\right)$ with increased levels of particle volatility. Other in situ observations of new particle formation in the free troposphere originate from altitudes below 12 km (Clarke et al., 1998, 1999; Clarke and Kapustin, 2002; Weber et al., 1995, 1999; Krejci et al., 2003; Crumeyrolle et al., 2010) or above $12 \mathrm{~km}$ (Hermann et al., 2003; Minikin et al., 2003), but mostly below the level of zero net radiative heating $(Q=0)$ and, i.e. at altitudes where sinking air motion or frequent cloud formation may remove or scavenge aerosol particles before they can reach the stratosphere.

Particles found in the (tropical) upper free troposphere generally consist of sulfuric acid, water, and organic compounds with some fraction of non-volatile materials (e.g. Murphy et al., 1998, 2006; Curtius et al., 2001b; Heald et al., 2005; Froyd et al., 2010; Borrmann et al., 2010). The non-volatile components may be soot, mineral dust, biomassburning residues, meteoric ablation condensates, inorganic salts, and others. However, according to recent measurements in the tropics by Borrmann et al. (2010) up to $50 \%$ of the submicron aerosol particles between $370 \mathrm{~K}$ and $440 \mathrm{~K}$ potential temperature $(\Theta)$ contain non-volatile residuals with the implication that these are not pure $\mathrm{H}_{2} \mathrm{SO}_{4}-\mathrm{H}_{2} \mathrm{O}$ solution droplets. Recent studies by English et al. (2011) support this by suggesting that micrometeorites dominate the aerosol properties in the stratosphere.

A major source for pure $\mathrm{H}_{2} \mathrm{SO}_{4}-\mathrm{H}_{2} \mathrm{O}$ solution droplets in the UT/TTL is homogeneous nucleation following the oxidation of precursor gases like $\mathrm{SO}_{2}, \mathrm{OCS}$, and $\mathrm{CS}_{2}$, and (Thomason and Peter, 2006; Wilson et al., 2008) from sea surface 
emissions or of anthropogenic origin, e.g. by gaseous pollution material which undergoes long range transport into the TTL (Law et al., 2010). Occasionally, $\mathrm{SO}_{2}$ is directly injected into the stratosphere from explosive volcanic eruptions (Wilson et al., 1993; Vernier et al., 2011). $\mathrm{SO}_{2}$ appears in the boundary layer in mixing ratios ranging from $20 \mathrm{pptv}$ to more than $1 \mathrm{ppbv}$. In urban, highly polluted environments, $\mathrm{SO}_{2}$ mixing ratios of up to several hundred ppbv can be reached (Seinfeld and Pandis, 2006). Boundary layer $\mathrm{SO}_{2}$ can be rapidly transported to the UT via deep convection (Thornton et al., 1997), when ingested by a cumulonimbus cloud $(\mathrm{Cb})$. Although $\mathrm{SO}_{2}$ will be scavenged and dissolved by cloud hydrometeors, owing to its moderate solubility, a fraction of $40-90 \%$ is able to reach the $\mathrm{Cb}$ anvil or the outflow region according to cloud-resolving model calculations (Barth et al., 2001). This is in reasonable agreement with estimates by Crutzen and Lawrence (2000). Another study (Ekmann et al., 2006) provided model calculations, according to which only $30 \%$ of $\mathrm{SO}_{2}$ reaches the top of a cloud. However, Crutzen and Lawrence (2000) and Barth et al. (2001) showed the removal strength of a soluble gas (such as $\mathrm{SO}_{2}$ ) by cloud elements to be controlled by the cloud acidity. Arnold et al. (1997) measured $\mathrm{SO}_{2}$ mixing ratios in the extra-tropical UT reaching up to $\sim 1 \mathrm{ppb}$.

Recent studies (e.g. Metzger et al., 2010; Kerminen et al., 2010) have argued that, in addition to sulfuric acid, organic molecules are likely involved in particle nucleation and growth. Although these studies focused on conditions in the lower troposphere, given the abundance of organic species that was found in UT/TTL aerosols (Murphy et al., 2006), it is conceivable that organic compounds are also involved in NPF occurring in the UT/TTL.

With respect to the physico-chemical processes underlying NPF from the gas phase several mechanisms have been under consideration. These are: (1) binary homogeneous nucleation of sulfuric acid and water (Weber et al., 1999), (2) ternary nucleation of sulfuric acid, water, and a third substance like ammonia (Merikanto et al., 2007) or an organic compound (Zhang et al., 2004; Ekman et al., 2008; Metzger et al., 2010; Kulmala et al., 2006; Kerminen et al., 2010), (3) ion-induced nucleation of $\mathrm{H}_{2} \mathrm{SO}_{4}-\mathrm{H}_{2} \mathrm{O}$ clusters (Lovejoy et al., 2004; Curtius et al., 2006; Kazil and Lovejoy, 2004; Kazil et al., 2006, 2007; Lee et al., 2003) and (4) the ionmediated nucleation scheme, which attempts to capture the interactions between vapors, neutral clusters, and charged species (Yu and Turco, 2001; Yu et al., 2010). Isobaric mixing of two saturated (or slightly subsaturated) air masses can result in supersaturation (e.g. with respect to $\mathrm{H}_{2} \mathrm{SO}_{4}$ ) and enhance the NPF processes considerably (Khosrawi and Konopka, 2003). However, English et al. (2011) found that the number concentration of particles with $d_{\mathrm{p}}>10 \mathrm{~nm}$ in the UT, and aloft, is predominantly controlled by coagulation, instead of nucleation.
Initialization of nucleation by ions, which are formed by cosmic rays or by lightning discharge in the atmosphere, has been suggested to be a key mechanism for NPF (Kirkby et al., 2011). Huntrieser et al. (2002) provided evidence that NPF might be strongly connected to lightning-induced physicochemical mechanisms in mid-latitude thunderstorms. They found elevated number concentrations of presumably newly formed particles $\left(>30000\right.$ particles per $\left.\mathrm{cm}^{3}\right)$ in the thunderstorm outflow concurrent with increased lighting-induced $\mathrm{NO}_{\mathrm{x}}\left(=\mathrm{NO}\right.$ and $\left.\mathrm{NO}_{2}\right)$ concentrations over Europe.

While condensation of supersaturated gases occurs onto pre-existing aerosol particles and cloud elements, it can also contributes to the growth of neutral and charged molecular clusters that have formed from the gas phase. The growth of these molecular clusters is, however, generally hindered by a nucleation barrier (Curtius, 2006). Ions potentially act as nucleation cores for the attachment of supersaturated gas phase molecules by reducing the height of the nucleation barrier (Lovejoy et al., 2004; Curtius et al., 2006). Thermodynamically, the ion-induced NPF process is more favorable than neutral homogeneous nucleation, but the maximum amount of particles produced via the ion pathway is limited by the ion production rate. Large ions have been detected by Eichkorn et al. (2002) in the upper troposphere. First aircraft measurements with an air ion spectrometer in mid-latitudes were performed by Mirme et al. (2010), who found that ions play only a minor role in NPF in the free troposphere. Whether this spatially limited data set is representative for other conditions, regions and altitudes remains to be shown as other in-situ observations (Kanawade and Tripathi, 2006) support the importance of ions in the NPF process.

This study presents the data from in situ measurements in the tropical UT/TTL over South and Central America, Australia and West Africa performed during the TROCCINOX, $\mathrm{SCOUT}^{-\mathrm{O}_{3}}$ and SCOUT-AMMA campaigns as well as during several scientific missions on board the NASA WB-57F, respectively. The data are discussed concerning the occurrence of NPF within the UT and TTL region. With this study the location, the occurrence abundance, the strength and duration of observed NPF events are analyzed. This work refines the general findings published by Borrmann et al. (2010), which are largely based on the same data sets as the one used here. Observations from two flights are discussed in detail, demonstrating several cases of recent NPF of variable strength. Studies with an aerosol nucleation model are presented for investigating the strength of NPF under various environmental conditions, and to investigate the simulation's sensitivity concerning used parameters and assumptions. The role of $\mathrm{SO}_{2}$ and pre-existing aerosol for the nucleation process in the UT/TTL is discussed, as is the presence of nucleation mode particles in ice clouds. 


\section{Field campaign data base and instrumentation}

\subsection{Campaign locations and research aircraft}

In order to obtain in situ field measurements within the TTL and the tropical UT the Russian high altitude research aircraft M-55 Geophysica operated at altitudes up to $20.5 \mathrm{~km}$. The DLR Falcon-20 covered the altitude range from the ground to the tropical middle troposphere reaching $11.5 \mathrm{~km}$. Both aircraft were deployed:

1. during the TROCCINOX-2 field campaign ("Tropical Convection, Cirrus, and Nitrogen Oxides Experiment"; January - March 2005, from Araçatuba, Brazil, at $21.1^{\circ} \mathrm{S}, 50.4^{\circ} \mathrm{W}$; cf. Schumann, 2005; Schumann and Huntrieser, 2007; http://www.atmos-chem-phys. net/special_issue $82 . h t m l)$ and

2. during the SCOUT-O $\mathrm{O}_{3}$ mission (November-December 2005, from Darwin, Australia, at $12.5^{\circ} \mathrm{S}, 130.8^{\circ} \mathrm{E}$; cf. Vaughan et al., 2008; Brunner et al., 2009; http://www. atmos-chem-phys.net/special-issue124.html) and

3. during SCOUT-AMMA (August 2006, from Ouagadougou, Burkina Faso, at $12.4^{\circ} \mathrm{S}, 1.5^{\circ} \mathrm{W}$; cf. Cairo et al., 2010a; http://www.atmos-chem-phys.net/ special-issue $125 . \mathrm{html}$ ).

All field missions aimed at investigations concerning the influence of tropical convection on the UT/TTL composition and its impact on the tropical stratosphere and the subtropical lowermost stratosphere. During the TROCCINOX measurement period the local meteorology was predominantly influenced by the quasi-stationary pressure systems, the "Bolivian high". Frequent MCS formation over the East of South America (partly covering Argentina, Brazil, Paraguay and Uruguay) occurred and influenced the probed air masses as well as isolated thunder storms (Konopka et al., 2007). These authors analyzed the air mass transport and mixing across the TTL over Brazil. The studies of Schiller et al. (2009) describe the transport and conversion of $\mathrm{H}_{2} \mathrm{O}$ (e.g. for the formation of $\mathrm{H}_{2} \mathrm{SO}_{4}$ ) in the TTL and the impact of this conversion on the stratospheric water budget.

An objective of the SCOUT-O ${ }_{3}$ campaign was the characterization of the "Hector" storm system that develops north of Darwin, over the Tiwi Islands, nearly on a daily basis during the pre-monsoon season (Connolly et al., 2006). The top of the developing storm cell is capable of reaching altitudes of up to $20 \mathrm{~km}$, which indicated that "Hector" could play an important role for the vertical transport of aerosol particles and trace gases into the TTL or into the lower stratosphere. Further information on the meteorological situation during SCOUT-O ${ }_{3}$ are provided by Brunner et al. (2009).

The air masses in the TTL over West Africa, during the SCOUT-AMMA mission, were strongly influenced by the Tropical Easterly Jet (TEJ) such that the air mass transport towards the Sahelian TTL predominantly originates from the
Asian UT/LS, driven by the South Asian monsoon (Cairo et al., 2010a). Fierli et al. (2011) provides indications for local convection, formed in the Sahelian region extending from Sudan to West Africa. This local convection may have been superimposed on a mainly zonal air mass transport that prevailed throughout the SCOUT-AMMA mission with direct impact on the composition of the tropical UT. More studies on the air masses which impact particularly the chemical composition of the trace gas and aerosol constituents in the West African TTL during SCOUT-AMMA are provided by Law et al. (2010).

The data obtained from measurements aboard the Geophysica which are included in the analyses of this study, cover 5 local and 4 transfer flights from TROCCINOX, 6 local flights from $\mathrm{SCOUT}^{-\mathrm{O}_{3}}$ as well as 5 local flights from SCOUT-AMMA. From the CPC measurements aboard the Falcon data of 11 local flights and 4 transfer flights from TROCCINOX as well as 8 local and 2 transfer flights from SCOUT-AMMA are analyzed. Details on the aircraft, the instrumentation, and the campaign deployments can be obtained for TROCCINOX from http://www.pa.op.dlr. de/troccinox/, for SCOUT-O 3 from http://www.ozone-sec. ch.cam.ac.uk/scout_03/ and for SCOUT-AMMA from http: //amma.igf.fuw.edu.pl/.

The NASA WB-57F was flown in a series of missions (Pre-AVE - Pre Aura Validation Experiment, AVE_0506 Aura Validation Experiment, CR-AVE - Costa Rica Aura Validation Experiment and TC4 - Tropical Composition, Cloud and Climate Coupling) aiming at aerosol measurements in the UT/TTL in the tropics of South and Central America. The flights originated from Houston, (USA) and San Jose (Costa Rica). Measurements are reported which were made south of $23^{\circ} \mathrm{N}$ and between $95.1^{\circ}$ and $78.2^{\circ} \mathrm{W}$ (around Central America) in January and February 2004, in June 2005, in January and February 2006 and during August 2007. Descriptions of the aircraft payload, objectives and data for these missions can be found at www.espo.nasa.gov.

\subsection{Instrumentation for submicron aerosol measurements}

Two COPAS (COndensation PArticle counting Systems) were operated as dual-channel continuous-flow condensation particle counters (CPCs) at altitudes between 12.0 and $20.5 \mathrm{~km}$ on board the Geophysica. The COPAS performance was characterized by extensive laboratory and airborne experiments (Curtius et al., 2005; Weigel et al., 2009). The set of CPCs installed on board the Falcon for measurements from ground level to $11.5 \mathrm{~km}$ altitude is described by Minikin et al. (2003), Fiebig et al. (2005), and Weinzierl et al. (2009).

The smallest detectable particle size of two COPAS channels were adjusted to $d_{\mathrm{p} 50}=6$ and $15 \mathrm{~nm}$ (at $150 \mathrm{hPa}$ operating pressure), where $d_{\mathrm{p} 50}$ denotes the particle diameter at which particles are detected with $50 \%$ efficiency. Correspondingly, the particle number concentrations resulting 
from COPAS measurements are denoted as $N_{6}$ (for submicron particles with $\left.d_{\mathrm{p}}>6 \mathrm{~nm}\right)$ and $N_{15}\left(d_{\mathrm{p}}>15 \mathrm{~nm}\right)$. Generally, CPC lower detection limits, as well as their maximum asymptotic counting efficiencies, were found to depend on the operating pressure (Hermann et al., 2005), which was accounted for in our data set according to Weigel et al. (2009). Both, the third and fourth COPAS channel were operated with a $d_{\mathrm{p} 50}$ of $10 \mathrm{~nm}$. One of these channels was equipped with an aerosol pre-heater (of $250^{\circ} \mathrm{C}$ ) to determine the nonvolatile aerosol fraction $N_{\mathrm{nv}}$ (Curtius et al., 2005; Borrmann et al., 2010). The working fluid for all COPAS channels was FC-43, (perfluoro-tributylamine), because of its advantageous particle activation behavior at pressures below $200 \mathrm{hPa}$ (Brock et al., 2000; Hermann et al., 2005).

Similar to the Geophysica CPCs, a CPC system on board the Falcon was operated at settings with $d_{\mathrm{p} 50}=4 \mathrm{~nm}, d_{\mathrm{p} 50}=$ $10 \mathrm{~nm}$ and $d_{\mathrm{p} 50}=13 \mathrm{~nm}$ (Minikin et al., 2003). Another CPC on board the Falcon was measuring the concentration of nonvolatile particles $N_{\mathrm{nv}}$ by heating the sampled ambient air to $250^{\circ} \mathrm{C}$ in a setup very similar to that on the Geophysica. The difference in the count results between two channels measuring with different $d_{\mathrm{p} 50}$ provides in general the concentration of nucleation mode particles $N_{\mathrm{NM}}$ which represents the number density of particles at sizes between about 4 and $10 \mathrm{~nm}$ (or $13 \mathrm{~nm}$ ) for the CPCs on the Falcon during SCOUTAMMA (TROCCINOX), and about 6 to $15 \mathrm{~nm}$ for the COPAS measurements. All particle concentration data in this paper are presented as number of particles per $\mathrm{cm}^{3}$ of air at ambient pressure and temperature. The measurements occurred at a rate of $1 \mathrm{~Hz}$ and are provided as 15 -s averages.

Due to payload limitations on the Geophysica we were not always able to operate all four COPAS channels which are pairwise integrated in two separate instrument boxes. In particular, no volatility measurements are available for the flights of 24 February 2005, and 7 August 2006. COPAS data are were rejected when the measurements were affected by aircraft exhaust plume crossing.

Results from measurements in the tropical UT/TTL region near Costa Rica are also included from the University of Denver instruments NMASS (Nuclei Mode Aerosol Spectrometer; Brock et al., 2000) and FCAS (Focused Cavity Aerosol Spectrometer; Jonsson et al., 1995). The NMASS consists of five continuous-flow condensation particle counters operated in parallel at a constant system pressure of $60 \mathrm{hPa}$. The NMASS automation controls the CPC saturatorcondenser temperature such that the NMASS CPCs 1 to 5 measure particle number concentrations with $d_{\mathrm{p} 50}$ of $5.3 \mathrm{~nm}$, $8.4 \mathrm{~nm}, 15 \mathrm{~nm}, 30 \mathrm{~nm}$ and $53 \mathrm{~nm}$ respectively. FCAS analyses scattered light by aerosol particles revealing aerosol size distribution between $0.06 \mu \mathrm{m}<d_{\mathrm{p}}<2 \mu \mathrm{m}$ within 31 detector channels (with mean $\Delta d_{\mathrm{p}} / d_{\mathrm{p}}=0.111$ ). NMASS and FCAS data which were acquired in recognized aircraft plumes and in air with relative humidity with respect to ice exceeding $95 \%$ were excluded.

\subsection{Instrumentation for cloud measurements}

Some of the encountered NPF events occurred inside clouds. For their characterization the cloud particle size distributions were measured by a Forward Scattering Spectrometer Probe (modified FSSP-100, Dye and Baumgardner, 1984; De Reus et al., 2009) during TROCCINOX. During $\mathrm{SCOUT}_{-} \mathrm{O}_{3}$ and -AMMA a Cloud Imaging Probe (CIP) was deployed besides the FSSP-100. The FSSP-100 measurement range covers particle diameters from $2.7 \mu \mathrm{m}$ to $30 \mu \mathrm{m}$ while the CIP detects and images particles with diameter from $25 \mu \mathrm{m}$ to $1.4 \mathrm{~mm}$. The methods applied for the data reduction of the FSSP-100 and CIP measurements and the corresponding error analyses are described in De Reus et al. (2009) and Frey et al. (2011).

In addition, the Multiwavelength Aerosol Scatterometer (MAS; Buontempo et al., 2006; Cairo et al., 2010b) was implemented on the Geophysica to detect the presence of clouds during flight. Responding to the presence of optically active particles with sizes above $0.2 \mu \mathrm{m}$ the MAS also provides measurements of aerosol backscatter and depolarization (at $532 \mathrm{~nm}$ and $1064 \mathrm{~nm}$ wavelengths) in the immediate vicinity $(3-10 \mathrm{~m})$ of the aircraft with $5 \mathrm{~s}$ time resolution and $5 \%$ accuracy.

\subsection{Instrumentation for gas phase tracer species and flight parameters}

Carbon dioxide $\left(\mathrm{CO}_{2}\right)$ measurements with $5 \mathrm{~s}$ time resolution were performed on board the Geophysica with the High Altitude Gas AnalyzeR (HAGAR, Riediger et al., 2000; Homan et al., 2010), which comprises a two-channel in situ gas chromatograph and a non-dispersive infrared absorption $\mathrm{CO}_{2}$ sensor (LICOR 6251). Carbon monoxide (CO) is measured by the COLD (Cryogenically Operated Laser Diode; Viciani et al., 2008) instrument with $0.25 \mathrm{~Hz}$ sampling rate, $1 \%$ precision, and with an accuracy of 6-9\%. The measurement of the ambient temperature was performed with the Thermo Dynamic Complex (TDC) probe with an accuracy of $0.5 \mathrm{~K}$ (Shur et al., 2007). Further relevant flight parameters are provided by the Geophysica navigational system Unit for Connection with the Scientific Equipment (UCSE, Sokolov and Lepuchov, 1998).

\section{Modeling tools for the case studies of new particle formation events}

One goal of the case studies presented below is to provide model estimates of new particle formation rates and corresponding concentrations based on microphysical processes for direct comparison with the in situ measured number densities $N_{\mathrm{NM}}$. Therefore, MAIA (Model of Aerosols and Ions in the Atmosphere) developed by Lovejoy et al. (2004) and Kazil et al. (2007) was applied. As input parameters for 
MAIA, in situ data and estimates of $\mathrm{SO}_{2}$ mixing ratios derived from FLEXPART/FLEXTRA model results were used.

\subsection{FLEXPART model for emission sensitivity studies}

Oxidation of $\mathrm{SO}_{2}$ to $\mathrm{H}_{2} \mathrm{SO}_{4}$ vapor with subsequent nucleation is considered as the process driving NPF events which are described in the presented case studies. Consequently, it is important to quantify the amount of $\mathrm{SO}_{2}$ which was available for oxidation in an air parcel along its trajectory until it was intercepted and sampled by the research aircraft. Estimates of anthropogenic $\mathrm{SO}_{2}$ emission source strengths from the EDGAR global inventory were used and the transport of air masses was simulated by means of the Lagrangian particle dispersion model FLEXPART (Stohl et al., 1998, 2005). So-called retro-plumes (cf. Stohl et al., 2003) were initialized at short time intervals along the flight tracks of the Geophysica. The simulations are based on operational wind field data from ECMWF with a horizontal resolution of $1^{\circ}$ globally and $0.5^{\circ}$ in the measurement area, and a time resolution of $3 \mathrm{~h}$. Generally 60 vertical levels were considered with additional 31 for the SCOUT-AMMA flights (due to ECMWF data which were available with increased vertical resolution for the SCOUT-AMMA campaign). Each simulation consists of the trajectories of 40000 air parcels that are released in the volume of air sampled by the aircraft instrumentation and tracked for 20 days backward in time. Stochastic fluctuations, obtained by solving Langevin equations, are superimposed on the grid-scale winds to represent transport by turbulent eddies (Stohl et al., 2005). A convection scheme (Emanuel and Živković-Rothman, 1999) is used to represent convective transport (Forster et al., 2007). This scheme does not resolve individual sub-grid-scale convective cells but represents the overall effect of convection in grid cells where convection is diagnosed by redistributing particles stochastically according to the convective mass fluxes determined by the Emanuel and Zivkoviæ-Rothman (1999) scheme.

The backward simulations yield an emission sensitivity (Stohl et al., 2005, 2006) which is proportional to the residence times of the air parcels in a particular 3-D grid cell. The value of this emission sensitivity is a measure for the simulated mixing ratio in the receptor volume that a source of unit strength in the respective grid cell would produce, disregarding loss processes. The emission sensitivity can be used to display the transport history. By multiplying the emission sensitivity near the ground with an emission flux (here, anthropogenic $\mathrm{SO}_{2}$ emissions from the EDGAR global inventory), maps of source contributions are obtained, which can be used to identify pollution sources. Spatial integration of the source contributions yields the simulated mixing ratio of a passive tracer (here, of all anthropogenic $\mathrm{SO}_{2}$ emissions accumulated over the past 20 days) along the flight track.

\subsection{FLEXTRA model for trajectory analyses}

The box model used to describe aerosol nucleation runs on single "representative" trajectories and requires meteorological data along these trajectories as input. To produce back trajectories of single air masses from along the flight track, we used the trajectory model FLEXTRA (Stohl et al., 1995, 2001), driven with the same meteorological input data as FLEXPART. These calculations are based only on the gridscale ECMWF winds and represent convection only to the extent resolved by the ECMWF data. Nevertheless, trajectories with strong ascent were found for the convectively influenced flight segments of interest. We furthermore subjectively selected those trajectories with the strongest ascent for the MAIA calculations, assuming that they best represent the overall lifting of NPF precursors into the UT/TTL, thus compensating for the fact that single trajectories cannot represent sub-grid-scale convective lifting. There was good qualitative agreement between the selected single strongly ascending trajectories calculated by the FLEXTRA and the FLEXPART model results for the corresponding flight segments, both indicating transport from the boundary layer in the same region.

\subsection{Physico-chemical model MAIA for neutral and ion-induced aerosol nucleation}

MAIA (Lovejoy et al., 2004; Kazil et al., 2007) describes oxidation of $\mathrm{SO}_{2}$ to gaseous $\mathrm{H}_{2} \mathrm{SO}_{4}$, nucleation of neutral and charged sulfuric acid-water aerosol particles, aerosol condensational growth, and coagulation of the freshly formed aerosol particles among each other and onto pre-existing particles. Nucleation is implemented in the model based on laboratory thermo-chemical data (Curtius et al., 2001a; Lovejoy and Curtius 2001; Froyd and Lovejoy 2003a and b; Hanson and Lovejoy, 2006) for $\mathrm{H}_{2} \mathrm{SO}_{4}$ uptake and loss by neutral and charged clusters with up to 2 and 5 sulfuric acid molecules, respectively. MAIA uses laboratory thermo-chemical data (Gibbs' free energy of formation) to describe the stability (decay probability) of the smallest neutral and charged clusters, which is essential for the reliable description of the nucleation process. Gibbs' free energy also gives the temperature dependence of the cluster stability. Hence MAIA describes neutral and charged nucleation down to the very low temperatures occurring in the upper troposphere and lower stratosphere. The thermo-chemical data for $\mathrm{H}_{2} \mathrm{SO}_{4}$ $\mathrm{H}_{2} \mathrm{O}$ uptake and loss by large $\mathrm{H}_{2} \mathrm{SO}_{4}-\mathrm{H}_{2} \mathrm{O}$ aerosol particles ( $\gg 5$ sulfuric acid molecules) originate from the liquid drop model and $\mathrm{H}_{2} \mathrm{SO}_{4}$ and $\mathrm{H}_{2} \mathrm{O}$ vapor pressures over bulk solutions. This was calculated with a computer code (provided by S. L. Clegg, personal communication, 2007) which adopts experimental data from Giauque et al. (1960) and Clegg et al. (1994). The thermo-chemical data for intermediate sized particles are a smooth interpolation (cf. Kazil et al., 2007) of the data for the small (neutral clusters with 2 and charged 
clusters with 5 sulfuric acid molecules) and large particles (with many more than 2 or 5 sulfuric acid molecules). The rate coefficients for sulfuric acid uptake and loss by the aerosol particles, for the coagulation of the aerosol particles, and for the recombination of the negatively charged aerosol with cations are calculated with the Fuchs formula for Brownian coagulation (Fuchs, 1964) and averaged over the equilibrium $\mathrm{H}_{2} \mathrm{O}$ content probability distribution of the aerosol. This simplification holds well in the troposphere up to UT/LS altitudes, where water is more abundant by orders of magnitude than sulfuric acid, so that the aerosol particles have ample time to equilibrate with respect to water uptake or loss before colliding with a $\mathrm{H}_{2} \mathrm{SO}_{4}$ molecule. The system of differential equations for the aerosol concentrations is integrated with the VODE (Variable-coefficient Ordinary Differential Equation) solver (Brown et al., 1989).

In summary, based on

1. the FLEXTRA derived estimates of temperature, relative humidity, and pressure, along a backward trajectory of air mass transport,

2. estimates of available $\mathrm{OH}$ (which is parameterized as a cosine of the solar zenith angle, in approximation of the diurnal cycle of $\mathrm{OH}$ in the troposphere after $\mathrm{Li}$ et al., 2005; Wang et al., 2008) and of pre-existing aerosol surface area,

3. cosmic ray induced ion production rates, calculated by a model of energetic particle transport in the Earth's atmosphere (O'Brien, 2005), which accounts for variations in cosmic ray intensity as function of latitude and altitude,

4. initial $\mathrm{SO}_{2}$ mixing ratios of $50 \mathrm{pptv}$ or $500 \mathrm{pptv}$, representing estimated minimum and maximum levels,

MAIA calculates the number of aerosol particles produced in a NPF event (per cubic centimeter and second) as a function of daytime along particular air parcel trajectories intersecting with the M-55 Geophysica flight path. The diameter size range of nucleation mode particles analyzed from the MAIA simulations coincides with the diameter size range of nucleation mode particles measured by COPAS.

One limitation of this approach is that as both model tools MAIA and FLEXTRA do not take into account that air masses are mixed with surrounding air. Particularly during uplift or when detrainment occurs, it is very likely that in reality the lifted air mass is diluted due to mixing with background air. One has to consider that the result of FLEXPART calculations concerning the $\mathrm{SO}_{2}$ mixing ratio represents a maximum value because $\mathrm{SO}_{2}$ removal is ignored. Air mass mixing and resulting dilution, however, is considered by the FLEXPART model. In contrast, the single trajectories resulting from FLEXTRA and the results from MAIA simulations cannot reflect changes in $\mathrm{SO}_{2}$ mixing ratios or aerosol surface area concentrations due to dilution or removal processes. Thus, the MAIA simulations of this work serve as a sensitivity study.

\section{Results and interpretations}

\subsection{Overview of the new particle formation events encountered in the tropics}

\subsubsection{Summary of tropical submicron particle measurements}

The vertical distribution of measured total submicron particle number concentration data are displayed in Fig. 1 as median profiles over all TROCCINOX (Fig. 1a) and SCOUTAMMA (Fig. 1b) flights. The data include all measurements from the Geophysica (number concentration $N_{6}$, for $\Theta>350 \mathrm{~K}$, above $\sim 11 \mathrm{~km}$ altitude) and the Falcon $\left(N_{4}\right.$ for $\Theta<350 \mathrm{~K})$. The measurements indicate a high variability in particle number concentrations at $\Theta<310 \mathrm{~K}$ (below $\sim 2 \mathrm{~km}$ altitude) ranging from 1000 to 40000 particles per $\mathrm{cm}^{3}$. A minimum with typically less than 1000 particles per $\mathrm{cm}^{3}$ is observed for $310 \mathrm{~K}<\Theta<330 \mathrm{~K}(\sim 2-6 \mathrm{~km})$ and a maximum in the altitude range, where NPF events were detected most frequently and with the largest number concentrations $(350 \mathrm{~K}<\Theta<370 \mathrm{~K}, \sim 11-15 \mathrm{~km})$. Generally, over West Africa and between $380 \mathrm{~K}$ and $420 \mathrm{~K}(\sim 16-18 \mathrm{~km})$ somewhat higher particle number concentrations were observed than over South America. Additionally, in Fig. 1c the vertical distribution of the particle number concentration from measurements with the University of Denver's NMASS is shown from measurements in the tropical UT/TTL region near Costa Rica. Displayed data show results from the first of five NMASS detection channels $\left(d_{\mathrm{p} 50}=5.3 \mathrm{~nm}\right)$. Note that in Fig. 1a and b the TROCCINOX and SCOUTAMMA datasets are displayed separately (distinguishing measurement locations and years) while the NMASS data set (Fig. 1c) is a composite of the measurements over $4 \mathrm{yr}$. The measurements with NMASS were performed almost at the same location in the tropics (Central America) including winter and summer seasons. However, the comparison reveals one common feature: the altitude level which is characterized by highest particles number concentrations $N_{6}$ ranges from $350 \mathrm{~K}$ ( $340 \mathrm{~K}$, for the SCOUT-AMMA observations) to $370 \mathrm{~K}$, the bottom of the TTL. The lower TTL boundary is located, according to the description by Fueglistaler et al. (2009), at the $355 \mathrm{~K}$ level where the main convective outflow occurs. Gettelman et al. (2004) define $350 \mathrm{~K}$ to be the isentropic level of main deep convective outflow which is in agreement with the findings by Law et al. (2010) for the particular case of the SCOUT-AMMA mission during the 2006 monsoon season over West Africa. 




Fig. 1. Vertical profiles of total particle number densities (for particle diameters larger than $6 \mathrm{~nm}$ for $\Theta>350 \mathrm{~K}$ and $4 \mathrm{~nm}$ for $\Theta<350 \mathrm{~K}$, and up to $\approx 1 \mu \mathrm{m}$ ) for all tropical flights of the M-55 Geophysica and the DLR Falcon-20 during (a) TROCCINOX and (b) SCOUT-AMMA. Median values are shown (black line), as well as 10th, 25th, 75th, 90th, and 99th percentiles (grey-scale contours). Frequent occurrence of New Particle Formation events (99th percentiles) influences the median over South America in the 11-13.5 km altitude range and over West Africa in the $9-14 \mathrm{~km}$ altitude range. (c) Measurement results from the NMASS (on the NASA WB-57F) over Central America between 2004 and 2007 indicating frequent occurrence of high particle number densities (for particle diameters $>5.3 \mathrm{~nm}$ ) in the same altitude band.

\subsubsection{Detection of NPF by the COPAS instrument and the DLR CPC system}

The abundance of nucleation mode particles is determined by the subtraction of aerosol number concentrations measured with two CPC channels of different $d_{\mathrm{p} 50}$ settings, respectively. For the COPAS system this is generally $N_{\mathrm{NM}}=N_{6-}$ $N_{15}$. For the DLR CPC system $N_{\mathrm{NM}}$ is obtained from the difference between $N_{4}$ and $N_{13}$ (TROCCINOX) or $N_{4}$ and $N_{10}$ (SCOUT-AMMA). It is important to note that in background conditions the COPAS channels with $d_{\mathrm{p} 50}=6 \mathrm{~nm}$ and $d_{\mathrm{p} 50}=15 \mathrm{~nm}$ show almost equal number concentrations, within the measurement uncertainties of $15 \%$ for each channel (Weigel et al., 2009). The same is valid for the DLR CPC system within a measurement uncertainty of $10 \%$.

For the COPAS measurement analysis a conservative definition of an NPF event is used, which includes the measurement uncertainty of $15 \%$ for each COPAS channel. Thus, a positive difference between $N_{6}$ and $N_{15}$ is only considered to be an NPF event if $0.85 \cdot N_{6}-1.15 \cdot N_{15}>0$ particles per $\mathrm{cm}^{3}$ (if $\geq 100$ particles per $\mathrm{cm}^{3}$, the NPF event is considered to be of high intensity). At background conditions, without NPF, the subtraction of number concentrations that are measured by two independently operated CPCs leads to positive and negative values of $N_{\mathrm{NM}}$ that statistically vary around zero. A similar NPF criterion was applied to the measure- ment data from the DLR CPC system, assuming an instrumental uncertainty of $10 \%$. For both instruments intentionally a more rigorous criterion was adopted for our data analysis which excludes the statistical fluctuations of the counters. NPF criteria, e.g. as suggested by Lee et al. (2003), on our measurements data would lead to more frequent identification of NPF events with longer duration of each event.

\subsubsection{Summary of NPF event data}

The number concentrations of nucleation mode particles $N_{\mathrm{NM}}$ during TROCCINOX and SCOUT-AMMA are shown as a function of potential temperature in Fig. 3a. Nucleationmode particles often occurred at the bottom of the TTL. The cold point tropopause was located at 360-385 K during TROCCINOX and SCOUT-AMMA, but generally not above $385 \mathrm{~K}$. Between $350 \mathrm{~K}$ and $370 \mathrm{~K} N_{\mathrm{NM}}$ peaks to values of 4000 to 8000 particles per $\mathrm{cm}^{3}$ with a maximum of $>16000$ particles per $\mathrm{cm}^{3}$ at $375 \mathrm{~K}$ which was observed during the flight on 27 January 2005. Similarly, the results for $N_{\mathrm{NM}}$ determined from measurements with the NMASS show the appearance of highest concentrations ( $>25000$ particles per $\mathrm{cm}^{3}$ ) of nucleation mode particles at altitudes below $385 \mathrm{~K}$. Concentrations $N_{\mathrm{NM}}$ that were measured aboard the Falcon (Fig. 3a) indicate numerous NPF events in the range between $340 \mathrm{~K}$ and $350 \mathrm{~K}$ exceeding the COPAS measurements at this 


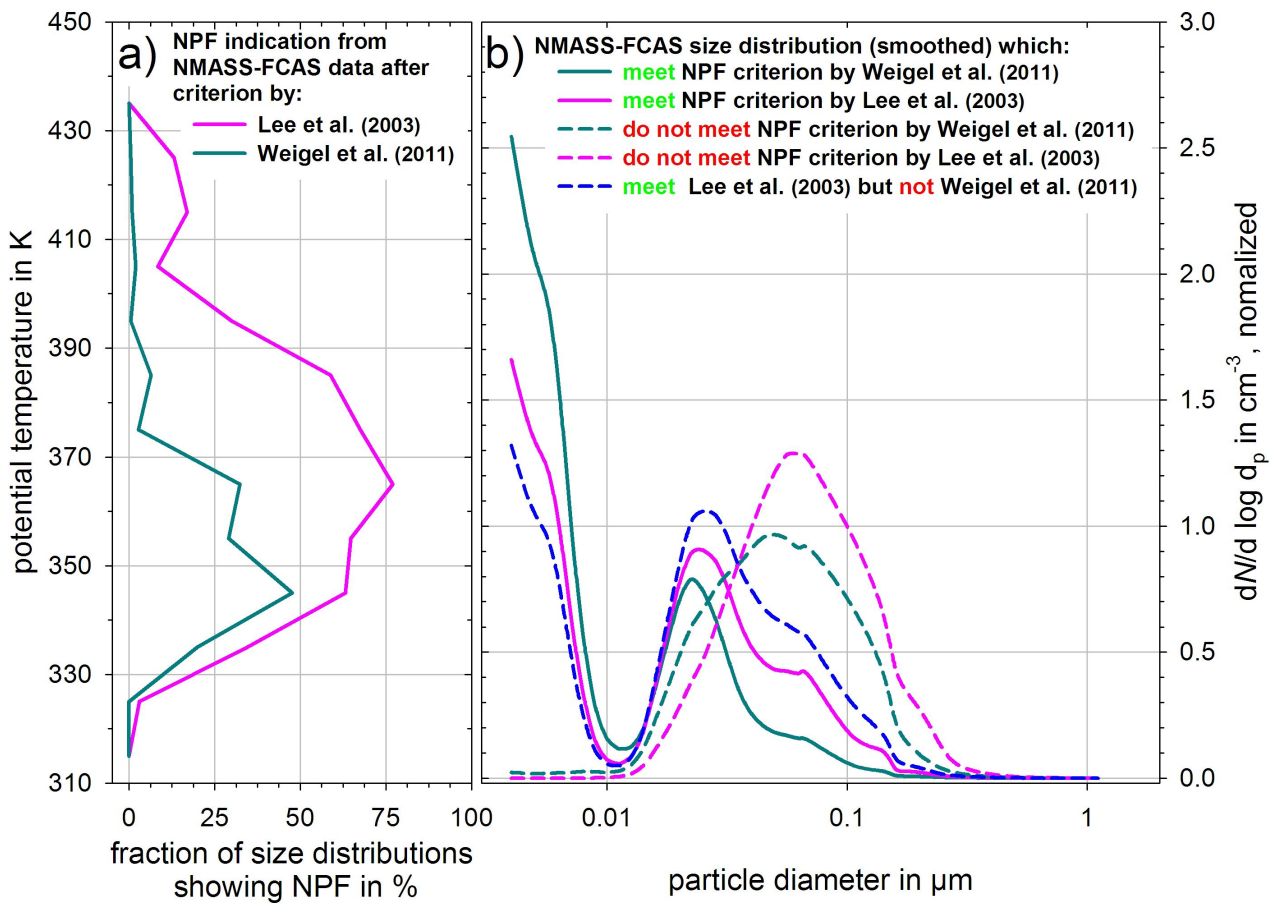

Fig. 2. Two different NPF criteria applied on NMASS-FCAS data measured on board the NASA WB-57F over Central America. (a) Fraction of 5530 aerosol size distributions that either meet the NPF criterion according to Lee et al. (2003) or the more conservative NPF criterion of the present work (labled "Weigel et al., 2011"). (b) Mean normalized and smoothed aerosol size distributions in the altitude range 325-395 K that satisfy or not one of these criteria.

altitude range. The Falcon conducted considerably more and longer measurements at this flight level during TROCCINOX and SCOUT-AMMA than the Geophysica $(\sim 31 \mathrm{~h}$ versus $\sim 4 \mathrm{~h}$ ) explaining the differences in the observations. Between $310 \mathrm{~K}$ and $340 \mathrm{~K}$ the occurrence of NPF is clearly reduced. A further distinct layer is shown by the CPC measurement data obtained aboard the Falcon with elevated $N_{\mathrm{NM}}$ reaching up to 23500 particles per $\mathrm{cm}^{3}$ between $300 \mathrm{~K}$ and $310 \mathrm{~K}$, which is data from inside the boundary layer and, therefore, are not analyzed in detail here.

With COPAS the NPF events were observed in the TTL region during 4 transfer flight sections and during 5 out of 9 local flights over South America as well as during each of the 5 local flights over West Africa, albeit with differing strength. The numbers of occurrences of NPF events throughout TROCCINOX and SCOUT-AMMA and statistical parameters concerning measured $N_{\mathrm{NM}}$ are summarized in Table 1. During NPF events, applying the $15 \%$-criterion (negative values of $N_{\mathrm{NM}}$ were set to zero), median $N_{\mathrm{NM}}$ were found to range between 200-900 particles per $\mathrm{cm}^{3}$ below $350 \mathrm{~K}$ (Fig. 3b). Between $355 \mathrm{~K}$ and $360 \mathrm{~K}$ NPF events with median $N_{\mathrm{NM}}$ of more than 1000 particles per $\mathrm{cm}^{3}$ were observed. Additionally, the variability in this altitude range is large, ranging from 250 particles per $\mathrm{cm}^{3}$ (25-percentile) up to 4000 particles per $\mathrm{cm}^{3}$ (75-percentile). Above $365 \mathrm{~K}$ until $385 \mathrm{~K}$ the median $N_{\mathrm{NM}}$ gradually decreases to 100 par- ticles per $\mathrm{cm}^{3}$. Above $385 \mathrm{~K}$ the frequency and strength of NPF events are reduced such that the median $N_{\mathrm{NM}}$ generally remains below 50 particles per $\mathrm{cm}^{3}$. Above $400 \mathrm{~K}$ the median $N_{\mathrm{NM}}$ do not exceed 20 particles per $\mathrm{cm}^{3}$, apart from the exceptional case of NPF occurrence on a flight section between Recife (Brazil) and Sal (Cape Verde) on 27 February 2005 reaching $N_{\mathrm{NM}}$ of $100-150$ particles per $\mathrm{cm}^{3}$ at the $415-420 \mathrm{~K}$ level. Moreover, this example demonstrates that elevated $N_{\mathrm{NM}}$ can also be observed at stratospheric altitudes. Whether or not these nucleation mode particles were originally formed in the stratosphere remains speculative.

In Fig. $3 \mathrm{~b}$ also the averaged $N_{\mathrm{NM}}$ determined from 68 $(>350 \mathrm{~K})$ and $266(<350 \mathrm{~K})$ single NPF events throughout TROCCINOX and SCOUT-AMMA are shown and colorcoded according to respective duration of each event. Summarizing, some additional information on temporal extensions of the observed NPF events at specific flight levels and related to the overall measurement time at respective flight level are provided in Table 1.

On a timescale of 1-2 days after burst-like NPF events most of the nucleation mode particles either coagulate or grow by condensation. Both would mean that particles disappear out of the nucleation mode diameter size range. Since the NPF were encountered often it is conceivable that such events occur frequently in the tropical upper troposphere. 




Fig. 3. (a) Colored circles: concentrations of nucleation mode particles, $N_{\mathrm{NM}}$, in the size range $6 \mathrm{~nm}<d_{\mathrm{p}}<15 \mathrm{~nm}$ (COPAS) of 9 tropical flights of the M-55 "Geophysica" during TROCCINOX (4 transfer and 5 local flights) and of 5 local flights during SCOUT-AMMA. Rose colored: $N_{\mathrm{NM}}\left(4 \mathrm{~nm}<d_{\mathrm{p}}<15 \mathrm{~nm}\right)$ from CPC measurements on the DLR Falcon-20 throughout both campaigns $(\Theta<350 \mathrm{~K})$. Grey colored: $N_{\mathrm{NM}}\left(5.3 \mathrm{~nm}<d_{\mathrm{p}}<15 \mathrm{~nm}\right)$ resulting from $4 \mathrm{yr}$ of measurements with the NMASS system (on the NASA WB-57F). (b) Solid lines: median vertical distribution of $N_{\mathrm{NM}}$ with 25th and 75th percentiles from COPAS measurements (black) and DLR Falcon-20 CPC measurements (red). Circles: averaged $N_{\mathrm{NM}}$ of single NPF events, color-coded according to the observed event duration. (c) Median vertical profile with 25 th and 75th percentiles of the number concentration $\left(N_{\mathrm{nv}}\right)$ of non-volatile particles with $d_{\mathrm{p}}>1,0 \mathrm{~nm}$. (d) Median vertical profile with 25 th and 75th percentiles of the fraction $f=N_{\mathrm{nv}} / N_{6}$ of non-volatile particles (black: COPAS measurements; red: DLR Falcon-20 CPC data). Squares with vertical bars: mean cold point tropopause (green: TROCCINOX; dark-red: SCOUT-AMMA) with bars denoting the highest and lowest encountered tropopause heights.

Analysis of the non-volatile particle distribution provides insight into the processes governing the budget for particle number concentration in the TTL, e.g. of aerosol transport from elsewhere versus local aerosol formation. Therefore, the measured vertical distribution of the median number concentration for non-volatile particles $N_{\text {nv }}$ is shown in Fig. 3c. In Fig. $3 \mathrm{~d}$ the ratio, $f$, of $N_{\mathrm{nv}}$ and $N_{6}$ (or $N_{4}$ for the DLRCPC) is displayed. The most intense events of NPF in the uppermost free troposphere and lower TTL region were encountered within a narrow altitude band, between $350 \mathrm{~K}$ and $360 \mathrm{~K}$. In the TTL between $360 \mathrm{~K}$ and $380 \mathrm{~K}$ nucleation mode particles were frequently found in quantities of several hundred up to thousands per $\mathrm{cm}^{3}$. With respect to particle volatility, the altitudes between $340 \mathrm{~K}$ and $360 \mathrm{~K}$ (Fig. 3c and d) appear to contain the lowest amounts of non-volatile particles. A similar minimum for $f$ has also been observed in the TTL over Northern Australia (Borrmann et al., 2010). At those levels where nucleation mode particles were detected relatively low fractions of non-volatile particles (with $f \approx 10$
$20 \%$ ) result. This is in agreement with the notion that freshly nucleated particles consist of solution droplets mainly containing substances which are entirely volatile at $250^{\circ} \mathrm{C}$.

\subsubsection{Relevance for the TTL}

The data indicate that the most intense NPF occurred at the bottom of the TTL $(355 \mathrm{~K}$ to $360 \mathrm{~K}$, cf. Fueglistaler et al., 2009) immediately above the main outflow region of tropical deep convection. For SCOUT-AMMA Fierli et al. (2011) showed by means of mesoscale model calculations that detrainment of convectively lifted air reached altitudes of $17 \mathrm{~km}$ and higher, significantly influencing the TTL over West Africa. Considering the outflow altitude range from $320 \mathrm{~K}$, for shallow convection, up to $350 \mathrm{~K}$, for deep convection (Law et al., 2010), it can be speculated that the minima in the particle volatility parameters $N_{\mathrm{nv}}$ and $f$ just above the level of convective outflow are caused by previous scavenging of non-volatile particles during convective air mass ascent. 
Table 1. Number of occurrences of a total of 68 single NPF events observed aboard the M-55 Geophysica and of 266 single NPF events observed aboard the DLR Falcon-20 as a function of potential temperature. The number concentration $N_{\mathrm{NM}}$ is given as the arithmetic mean together with the maximum and minimum value of $\mathrm{N}_{\mathrm{NM}}$ reached in each $\Theta$-bin. The "NPF duration" is given as range between shortest and longest duration of an event with a total NPF duration for each $\Theta$-bin. The total measurement time reflects the residence time of the two aircraft in each $\Theta$-bin throughout the TROCCINOX and SCOUT-AMMA mission.

\begin{tabular}{|c|c|c|c|c|c|c|c|c|}
\hline & \multirow[t]{2}{*}{$\Theta$ range in $\mathrm{K}$} & \multirow{2}{*}{$\begin{array}{l}\text { number of } \\
\text { NPF events }\end{array}$} & \multicolumn{3}{|c|}{ concentration in $\mathrm{cm}^{-3}$} & \multirow{2}{*}{$\begin{array}{l}\text { NPF duration } \\
\text { range in s } \\
\end{array}$} & \multirow{2}{*}{$\begin{array}{l}\text { total NPF } \\
\text { duration in } \mathrm{s}\end{array}$} & \multirow{2}{*}{$\begin{array}{r}\text { total measurement } \\
\text { time in s }\end{array}$} \\
\hline & & & $\bar{N}_{\mathrm{NM}}$ & $N_{\mathrm{NM}}^{\min }$ & $N_{\mathrm{NM}}^{\max }$ & & & \\
\hline \multirow{8}{*}{ 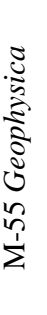 } & $430-440$ & 1 & 11 & 11 & 11 & 15 & 15 & 2910 \\
\hline & $420-429$ & 1 & 15 & 15 & 15 & 120 & 120 & 8250 \\
\hline & $410-419$ & 2 & 110 & 63 & 228 & $390-1710$ & 2100 & 22425 \\
\hline & 390-399 & 4 & 28 & 12 & 43 & $15-90$ & 135 & 33975 \\
\hline & $380-389$ & 1 & 64 & 33 & 423 & $15-705$ & 1845 & 22590 \\
\hline & $370-379$ & 13 & 205 & 23 & 1164 & $15-1935$ & 3795 & 24435 \\
\hline & $360-369$ & 18 & 825 & 24 & 6777 & $15-1290$ & 6150 & 28005 \\
\hline & $350-359$ & 16 & 2114 & 81 & 16517 & $15-2610$ & 6930 & 24900 \\
\hline \multirow{6}{*}{ 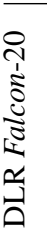 } & $340-349$ & 191 & 392 & 100 & 4812 & $20-1500$ & 25620 & 111550 \\
\hline & 330-339 & 25 & 271 & 100 & 2881 & $20-310$ & 1570 & 19450 \\
\hline & $320-329$ & 7 & 373 & 123 & 1022 & $20-230$ & 440 & 12100 \\
\hline & $310-319$ & 6 & 458 & 106 & 1548 & $20-50$ & 200 & 14250 \\
\hline & $300-309$ & 26 & 2644 & 106 & 23572 & $20-420$ & 1370 & 9390 \\
\hline & 290-299 & 5 & 587 & 119 & 2380 & $20-100$ & 250 & 740 \\
\hline
\end{tabular}

Thus, is seems conceivable that large numbers of nucleation mode particles are found in the convective outflow regions because these particles where either freshly formed there or represent a remaining fraction of particles which were not removed by uptake from cloud elements. Furthermore, the region of tropical convective outflow is, due to in-cloud scavenging, affected by a minimum of nonvolatile particles that can act as potential condensation surfaces. Concurrently, the ambient temperatures may be low enough that NPF precursor gas concentrations are supersaturated in the UT and lowermost TTL. Refining the original findings by Brock et al. (1995), we observe that the particles seem to be mostly produced in the lowest parts of the TTL and in the tropical UT. Fractions of these newly formed particles are then amenable for being transported upward through the TTL and could reach the stratosphere (Fueglistaler et al., 2009; Borrmann et al., 2010).

The highest concentrations of nucleation mode particles $N_{\mathrm{NM}}$ were found to occur within considerable spatial range during two flights on 24 February 2005 (TROCCINOX, South America) and on 7 August 2006 (SCOUT-AMMA, West Africa). These two flights were therefore selected for detailed case studies, but also because of the strength of the observed NPF events. Moreover, the second flight allows for studying the presence of nucleation mode particles within clouds.

\subsection{Case studies of three NPF events over South America and over West Africa}

Three cases of NPF encounters are discussed here, one observed over South America (Case 1) and the other two over West Africa (Cases 2 and 3).

On 24 February 2005 (Case 1) the first post-mission transfer flight of the Geophysica was performed from Araçatuba $\left(21^{\circ} \mathrm{S}\right)$ to Recife $\left(8^{\circ} \mathrm{S}\right)$, Brazil. On this day the meteorological situation over Brazil was dominated by a Bolivian high that supported the advection of air masses from the $\mathrm{Pa}$ cific, passing over central Argentina in a counter-clockwise turn towards the Atlantic and northward along the Brazilian East coast. A trough was northward moving along the eastern part of Brazil connected with isolated thunderstorms over the Amazon Basin, over North East Argentina $\left(\sim 28^{\circ} \mathrm{S}\right)$ and over the Atlantic $\left(\sim 23^{\circ} \mathrm{S}\right)$.

One local flight over West Africa (10-13 $\mathrm{N}$ and 1.5$8^{\circ} \mathrm{W}$ ) on 7 August 2006 (Case 2 and 3) was focused on measurements at the cloud top and in the outflow region of a dissolving intense MCS over southern Mali (Cairo et al., 2010a; Fierli et al., 2011). The flight track of the Geophysica followed a direct approach towards the region above the MCS top and the subsequent flight section allowed for measurements with increasing distance from the MCS. Finally, a new approach to the region above the same MCS was performed before the Geophysica turned back to the mission base. The level of main outflow of this MCS was located at the $353 \mathrm{~K}$ level according to Fierli et al. (2011). These 




Fig. 4. Cases of increased concentration of nucleation mode particles indicating New Particle Formation (NPF - shaded areas): (a) Case 1 during the flight from Araçatuba to Recife, Brazil, on 24 February 2005 (TROCCINOX). (b) Cases 2 and 3 during a local flight over West Africa on 7 August 2006 (SCOUT-AMMA). The difference in particle concentrations, $N_{6}-N_{15}$, is indicative of recent NPF. Lines: grey flight altitude; dark cyan - ambient temperatures; blue - in situ measured $\mathrm{CO}_{2}$ mixing ratio (not available for the SCOUT-AMMA flight on 7 August 2006). Green dots: flight time period inside a cirrus cloud as indicated by $N_{>2} \mu \mathrm{m}$ measured by FSSP-100. Gaps in the $N_{6}$ time series of (b) are caused by discarding data in case the measurements were affected by electronic noise.

authors investigate the convective uplift of air masses due to this particular MCS and find highly variable convective ages from a few up to $48 \mathrm{~h}$.

\subsubsection{In situ measurements from South America}

During the Geophysica flight on 24 February 2005 at $\sim 13 \mathrm{~km}$ altitude large concentrations (up to 7700 particles $\mathrm{cm}^{-3}$ ) of nucleation mode particles were observed, indicating recent NPF (Case 1). The measured data are displayed in Fig. 4a together with other relevant variables. During Case 1, at $\sim 14$ :15 UTC, a cirrus cloud was encountered which is indicated by FSSP-100 measurements of increased number concentrations $\left(N_{>2} \mu \mathrm{m}\right)$ of particles with $d_{\mathrm{p}}>2 \mu \mathrm{m}$.

The large concentrations of nucleation mode particles over South America are correlated with lower $\mathrm{CO}_{2}$ concentrations indicating a different air mass history for those air masses in which NPF occurred. It is not possible to relate the decreased $\mathrm{CO}_{2}$ concentrations to specific sinks at ground due to the strong variability of the various sources and sinks of
$\mathrm{CO}_{2}$, e.g. diurnal cycles, distribution of vegetation, etc. The reduced $\mathrm{CO}_{2}$ concentrations in the sampled air masses, however, are indicative for $\mathrm{CO}_{2}$ uptake by vegetation and thus, the low $\mathrm{CO}_{2}$ concentrations also indicate that the sampled air recently had contact with the boundary layer and most likely was carried aloft to the measurement altitudes.

\subsubsection{In situ measurements from West Africa}

On 07 August 2006 two pronounced NPF events with concentrations up to 4000 particles $\mathrm{cm}^{-3}$ were observed in the altitude range of $12 \mathrm{~km}$ to $14 \mathrm{~km}$ (cf. Fig. $4 \mathrm{~b}$, Case 2 and Case 3). The measurements of Case 2 were recorded during a period of level flight at $\sim 13.5 \mathrm{~km}$ followed by a descent to $12 \mathrm{~km}$ and re-ascent between 13:55 and 14:16 UTC. According to measurements by MAS immediately before and after this NPF Case 2 increased backscatter and depolarization were observed, indicative for having passed a field of very thin clouds. 
Furthermore, NPF was observed during the descent period at $13.5 \mathrm{~km}$ to $12 \mathrm{~km}$ altitude between 15:35 and 15:40 UTC (Case 3). During Case 3 the anvil of a Mesoscale Convective System (MCS) was partly crossed. The anvil contained many particles with large sizes constituting a correspondingly large surface area capable of scavenging newly formed nucleation mode particles. The high values of depolarization (cf. Sect. 5.4) measured by MAS indicate the presence of aspherical particles, i.e. ice, inside the cloud.

\subsection{Transport model calculations and estimation of $\mathrm{SO}_{2}$ loadings}

The FLEXPART results for the cases from South America and West Africa are shown in Fig. 5, with superimposed flight altitude (black line). The colored columns show $\mathrm{SO}_{2}$ tracer mixing ratios simulated by FLEXPART along the flight track, with the colors indicating the time in days since emission of the $\mathrm{SO}_{2}$ from the surface according to the EDGAR inventory (cf. Sect. 3.1). Since $\mathrm{SO}_{2}$ was carried as a passive tracer, the mixing ratios represent the total exposure of the sampled air mass to $\mathrm{SO}_{2}$ emissions over the last 20 days. Real $\mathrm{SO}_{2}$ mixing ratios at the sampling locations would likely have been lower because of loss processes both within the boundary layer and during uplift to the flight altitude.

The calculations with the FLEXPART model as presented in Fig. 5 indicate that the air parcels probed during the NPF events have contained potential maxima of $\mathrm{SO}_{2}$, i.e. $\sim 0.6 \mathrm{ppbv}$ and $\sim 1.4 \mathrm{ppbv}$ for the case studies of South America and West Africa, respectively. The air masses were lifted to the measurement altitude within the last 4 to 7 days, either by convective or by slower, synoptic scale lifting. Both lifting processes are considered within the FLEXPART simulations, nevertheless, it is impossible to quantify (i.e. by a lifting rate) respective contribution to the resulting uplift. For the TROCCINOX case in the upper panel of Fig. 5 the highest source contributions of $\mathrm{SO}_{2}$ were located along West Brazil and Peru. For the SCOUT-AMMA study in the lower panel the $\mathrm{SO}_{2}$ source contributions were located in East Africa and East India/South-East Asia. The latter is in qualitative agreement with the calculations by Law et al. (2010), who showed that $\sim 40 \%$ of the air masses in the mid-TTL over West Africa during SCOUT-AMMA were influenced by injection of lower tropospheric air from Asia and India, while Fierli et al. (2011) concluded that over Africa regional deep convection played a role as well. In Fig. 5c) the measured $N_{\mathrm{NM}}$ for all NPF cases are shown versus the predicted $\mathrm{SO}_{2}$ mixing ratio along the flight track of the Geophysica for the TROCCINOX campaign. FLEXPART simulations for SCOUT-AMMA were made only for one selected flight. When NPF was observed while $\mathrm{SO}_{2}$ was predicted to be lower than $0.1 \mathrm{ppbv}$ this can still be sufficient for (moderate) NPF if other conditions promoting particle formation are favorable (low temperature, low condensation sink from pre- existing particle surfaces and high relative humidity) (Kirkby et al., 2011). However, whenever FLEXPART predicted $\mathrm{SO}_{2}$ to be elevated ( $>0.1 \mathrm{ppbv}$ ) along the flight track, NPF was observed.

\subsection{MAIA simulations of new particle formation over Brazil and West Africa}

The purpose of the MAIA simulations is to investigate whether ion-induced and neutral aerosol formation from $\mathrm{H}_{2} \mathrm{SO}_{4}$ and $\mathrm{H}_{2} \mathrm{O}$ suffices to explain the measured concentrations of nucleation mode particles $\left(N_{\mathrm{NM}}=N_{6}-N_{15}\right)$. The MAIA simulations (cf. Sect. 3.3; Lovejoy et al., 2004; Kazil and Lovejoy, 2004) are based on selected individual air mass trajectories as obtained from FLEXTRA (cf. Sect. 3.2; Stohl et al., 1995) which end at locations where NPF was observed by the Geophysica instrumentation. In Fig. 6 the pathway of these trajectories towards the Geophysica flight tracks are displayed over 10 days prior to the measurement and colored according to the potential temperature along respective trajectory in order to illustrate the air mass vertical movement.

For new particle formation observed during Case 1, two different air mass trajectories were considered. The first trajectory originates from the west coast of South America, i.e. Peru, and exhibits spatially extended and slow uplift towards the flight path. Most other trajectories for this NPF observation (Case 1) underwent convective lifting starting over the Pacific Ocean, more than $2500 \mathrm{~km}$ west of South America's coast. Due to oceanic emissions of dimethylsulfide (DMS, Charlson et al., 1987) which is oxidized to $\mathrm{SO}_{2}$, the Pacific trajectories did not necessarily carry much less $\mathrm{SO}_{2}$ compared to the Peruvian trajectory. The MAIA calculations for the two SCOUT-AMMA NPF observations (Cases 2 and 3, cf. Fig. 7c and d) are based on one air mass trajectory for each case. For the Case 2 and Case 3 trajectories the FLEXTRA calculations indicated recent convective uplift. For Case 2 the air mass originated over the African continent, in Central Sudan (cf. Fig. 6) moving at low levels towards North Ethiopia and Eritrea before convective uplift occurred over North Ethiopia 4 days before sampling (cf. Fig. 7c). In the North of Ethiopia (i.e. Dabbahu rifting zone of the NubiaArabia Plate boundary, Afar region) a volcanically active region is located (Hamling et al., 2009; Ferguson et al., 2010), and volcanic emission potentially contributed to the air mass $\mathrm{SO}_{2}$ loading. As the trajectory narrowly passes also the Red Sea coast natural $\mathrm{SO}_{2}$ sources (by DMS) or, as the Red Sea is a highly frequented route of sea going ships, a contribution of anthropogenic $\mathrm{SO}_{2}$ emission is conceivable. According to the FLEXTRA calculations for Case 3 the origin of the air masses was over the Bay of Bengal 10 days earlier. The trajectory describes a cyclonic turn partly crossing Myanmar, Bangladesh and India while continuously ascending over land, reaching peak altitude about 4.5 days before the sampling. Thus, $\mathrm{SO}_{2}$ from natural as well as anthropogenic sources over sea or of pollution from the Asian 
Table 2. Input parameters for MAIA model runs for calculations of the ion-induced and neutral aerosol nucleation for the case studies displayed in Fig. 7. Values of temperature $(T)$, pressure $(p)$ and relative humidity with respect to water $\left(\mathrm{RH}_{\mathrm{W}}\right)$ are given at the time the NPF is initialized after convective uplift. Water vapor and $\mathrm{OH}$ are given in number of molecules per $\mathrm{cm}^{3}$ of air.

\begin{tabular}{|c|c|c|c|c|c|c|c|}
\hline \multirow[b]{2}{*}{ trajectories end date and time (UTC) } & \multirow[b]{2}{*}{$\begin{array}{l}\text { Fig. } 7 \\
\text { panel }\end{array}$} & \multicolumn{6}{|c|}{ initial conditions at trajectory start } \\
\hline & & $\begin{array}{l}T \\
\text { in } \mathrm{K}\end{array}$ & $\begin{array}{l}p \text { in } \\
\mathrm{hPa}\end{array}$ & $\begin{array}{l}\mathrm{RH}_{\mathrm{W}} \\
\text { in } \%\end{array}$ & $\begin{array}{l}\mathrm{H}_{2} \mathrm{O} \text { vapor } \\
\text { in } \mathrm{cm}^{-3}\end{array}$ & $\begin{array}{l}\text { noon } \mathrm{OH} \\
\text { in } \mathrm{cm}^{-3}\end{array}$ & $\begin{array}{l}\text { ion pair production } \\
\text { rate in } \mathrm{cm}^{-3} \mathrm{~s}^{-1}\end{array}$ \\
\hline 24 Feb 2005, 14:13:17 & (a) & 227 & 295 & 62 & $6.1 \times 10^{15}$ & $10^{6}$ & 18.1 \\
\hline 24 Feb 2005, 14:16:34 & (b) & 227 & 171 & 41 & $2.7 \times 10^{14}$ & $10^{6}$ & 23.8 \\
\hline 7 Aug 2006, 14:09:30 & (c) & 227 & 240 & 48 & $2.4 \times 10^{15}$ & $10^{6}$ & 24.1 \\
\hline 7 Aug 2006, 15:36:44 & (d) & 227 & 161 & 59 & $1.9 \times 10^{15}$ & $10^{6}$ & 21.1 \\
\hline
\end{tabular}

continent could have been transported into the TTL, as also indicated by Law et al. (2010) who concluded that pollution sources in Asia influence the TTL composition over Africa.

Table 2 provides a summary of the initial parameters for the MAIA runs. The values listed for water vapor, pressure, and temperature are derived from the FLEXTRA trajectories. The noon $\mathrm{OH}$ concentration represents the peak value in the parameterization of $\mathrm{OH}$ as a function of the cosine of the solar zenith angle. A zero $\mathrm{OH}$ concentration is assumed at nighttime. The ion pair production rate due to cosmic rays is calculated in the course of the MAIA runs (cf. Sect. 3.3). The $\mathrm{SO}_{2}$ mixing ratios obtained from the FLEXPART runs likely represent an upper limit, because the reduction of $\mathrm{SO}_{2}$ due to air mass mixing and cloud processing are not accounted for. In previous simulations of convective clouds Ekman et al. (2006) found $\mathrm{SO}_{2}$ mixing ratios in the outflow region to be reduced to $\sim 30 \%$ of initial surface values, or $62 \mathrm{pptm}$ ( $\sim 28 \mathrm{pptv})$. With these comparably low $\mathrm{SO}_{2}$ mixing ratios in the outflow region, nevertheless, Ekman et al. (2006) predicted high $N_{\mathrm{NM}}$ due to NPF. Therefore, two initial $\mathrm{SO}_{2}$ mixing ratios of 50 and 500 pptv are used in the MAIA simulations (red and black lines in Fig. 7, respectively). The lower mixing ratio of $50 \mathrm{pptv}$ represents a case with depletion of $\mathrm{SO}_{2}$ by cloud processes. The higher mixing ratio of $500 \mathrm{pptv}$ represents a case of elevated upper tropospheric $\mathrm{SO}_{2}$.

$\mathrm{SO}_{2}$ mixing ratios in polluted industrial outflow measured in the boundary layer over the Bay of Bengal can exceed values of $1.5 \mathrm{ppbv}$ (Lelieveld et al., 2001). Pollution emissions of $\mathrm{SO}_{2}$ from Peruvian copper smelters were observed over 10 months to release a mean daily $\mathrm{SO}_{2}$ burden of $0.2-3 \mathrm{Gg}$ per day (Carn et al., 2007) and by a 6 month lasting study at a Peruvian measurement site (Marcapomacocha) a median $\mathrm{SO}_{2}$ mixing ratio was determined to range at about $3 \mathrm{ppbv}$ (Carmichael et al., 2003). Thus, even considering $\mathrm{SO}_{2}$ loss during the transport into the TTL, it is plausible that polluted air masses from Asia or Peru reach the TTL with a $\mathrm{SO}_{2}$ mixing ratio which differs not too much from the upper limit of estimated pre-existing $\mathrm{SO}_{2}$ mixing ratio for the MAIA simulations (i.e. 500 pptv). In contrast, the $\mathrm{SO}_{2}$ loading of air masses over East Africa (Sudan, Ethiopia and Eritrea) or over the Pacific Ocean might be less intense, such that these air masses, when reaching the TTL, may contain significantly less $\mathrm{SO}_{2}$ compared to Asian or Peruvian air masses, probably in quantities close to the lower limit of assumed pre-existing $\mathrm{SO}_{2}$ mixing ratio for the MAIA simulations (i.e. $50 \mathrm{pptv}$ ).

Since pre-existing surface area (in $\mu \mathrm{m}^{2}$ per $\mathrm{cm}^{3}$ of air) of the background aerosol constitutes a sink for gaseous $\mathrm{H}_{2} \mathrm{SO}_{4}$ and the highly mobile newly formed particles, five different simulations were performed, varying the initial aerosol surface area, using values of $0.5,1,2,4$, and $8 \mu \mathrm{m}^{2} \mathrm{~cm}^{-3}$. The maximum and minimum values for the pre-existing surface area (i.e. 0.5 and $8 \mu \mathrm{m}^{2} \mathrm{~cm}^{-3}$ ) were chosen with the aim to cover a representative range that is realistic and that naturally prevails from boundary layer up to $13-15 \mathrm{~km}$ altitude. These aerosol surface area densities change in the course of the runs due to growth and coagulation of the pre-existing aerosol particles. The purpose of choosing a broad range as initial assumptions for the MAIA calculations is to compensate for the neglected mixing and dilution processes in the simulations. The results of the simulations are shown in Fig. 7. Each panel displays the number of nucleation mode particles $\left(N_{6}-N_{15}\right)$ per $\mathrm{cm}^{3}$ predicted by MAIA due to ioninduced and neutral nucleation as a function of time. At time zero the air parcel was sampled by the instrumentation on board the aircraft.

For completeness, MAIA simulations were conducted on both trajectories for the Case 1, along the Peruvian and the Pacific trajectory, respectively. For the MAIA simulations concerning the SCOUT-AMMA cases the trajectory originating from East Africa (Case 2 - Fig. 7c) and the Bay of Bengal (Case Fig. 7d) are considered.

Notably, the increase of $N_{\mathrm{NM}}$ predicted by MAIA starts temporally staggered. The time that is needed for the formation of molecular clusters, for their growth to stable but very small particles $(1.5 \mathrm{~nm})$ and for further growth until reaching sizes between $6-15 \mathrm{~nm}$ is governed by the abundance of gaseous $\mathrm{H}_{2} \mathrm{SO}_{4}$. Additionally, the number of formed clusters and small particles influence the time that is needed for particles to grow to nucleation mode sizes. 


\section{age in days}
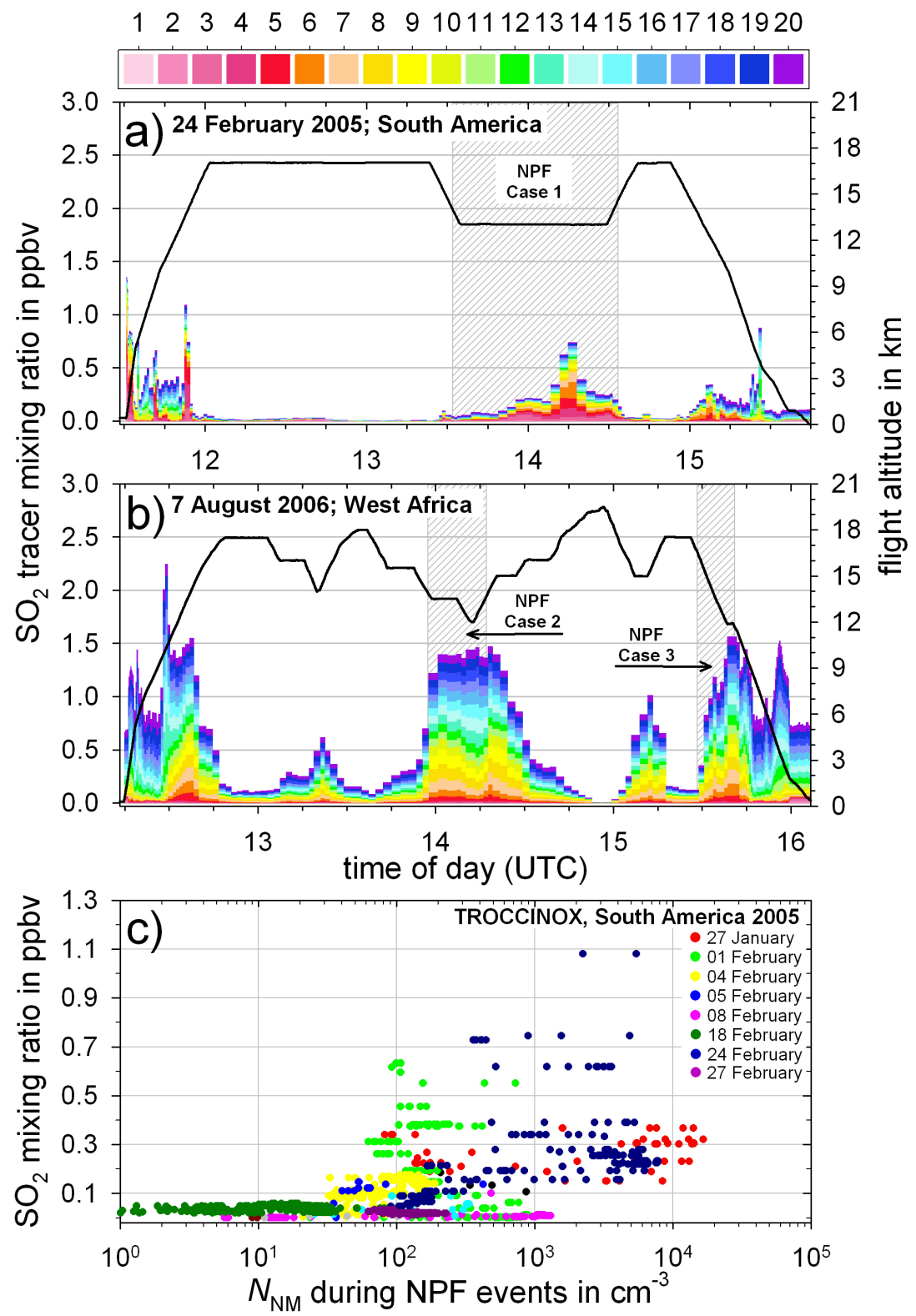

Fig. 5. FLEXPART trajectory model simulation of $\mathrm{SO}_{2}$ mixing ratio (upper envelope of colored regions) along the flight track (black line). (a) TROCCIONOX NPF event Case 1. (b) SCOUT-AMMA NPF event Cases 2 and 3. FLEXPART predicts high $\mathrm{SO}_{2}$ values exactly for the NPF events. Color code: age along trajectory since most previous $\mathrm{SO}_{2}$ emission (see text for details). (c) Relation between $N_{\mathrm{NM}}$ during $\mathrm{NPF}$ and predicted $\mathrm{SO}_{2}$ by FLEXPART. When $\mathrm{SO}_{2}$ mixing ratios were predicted to be enhanced NPF was observed.

\subsubsection{Results of the MAIA simulations for the NPF events}

The maximum of NPF predicted by the nucleation model appears several days (e.g. up to 6.5 days, cf. Fig. $7 b$ ) before the actual measurement. The temporal evolution of $N_{\mathrm{NM}}$ strongly depends on the history of the respective trajectory, on the pre-existing aerosol surface area, and on the initial concentration of $\mathrm{SO}_{2}$. The resulting number concentration
$N_{\mathrm{NM}}$ at time zero predicts the quantity of nucleation mode particles at the location of the flight track of the Geophysica where NPF has been detected by COPAS.

The aerosol nucleation model predicts maxima of $N_{\mathrm{NM}}$ due to NPF ranging up to $30000-40000$ particles $\mathrm{cm}^{-3}$. These values arise with $0.5 \mu \mathrm{m}^{2} \mathrm{~cm}^{-3}$ of pre-existing aerosol surface area and $\mathrm{SO}_{2}$ concentrations of $500 \mathrm{pptv}$, i.e. under maximum available $\mathrm{SO}_{2}$ and minimum background aerosol surface area. In contrast, if initial $\mathrm{SO}_{2}$ concentrations of 


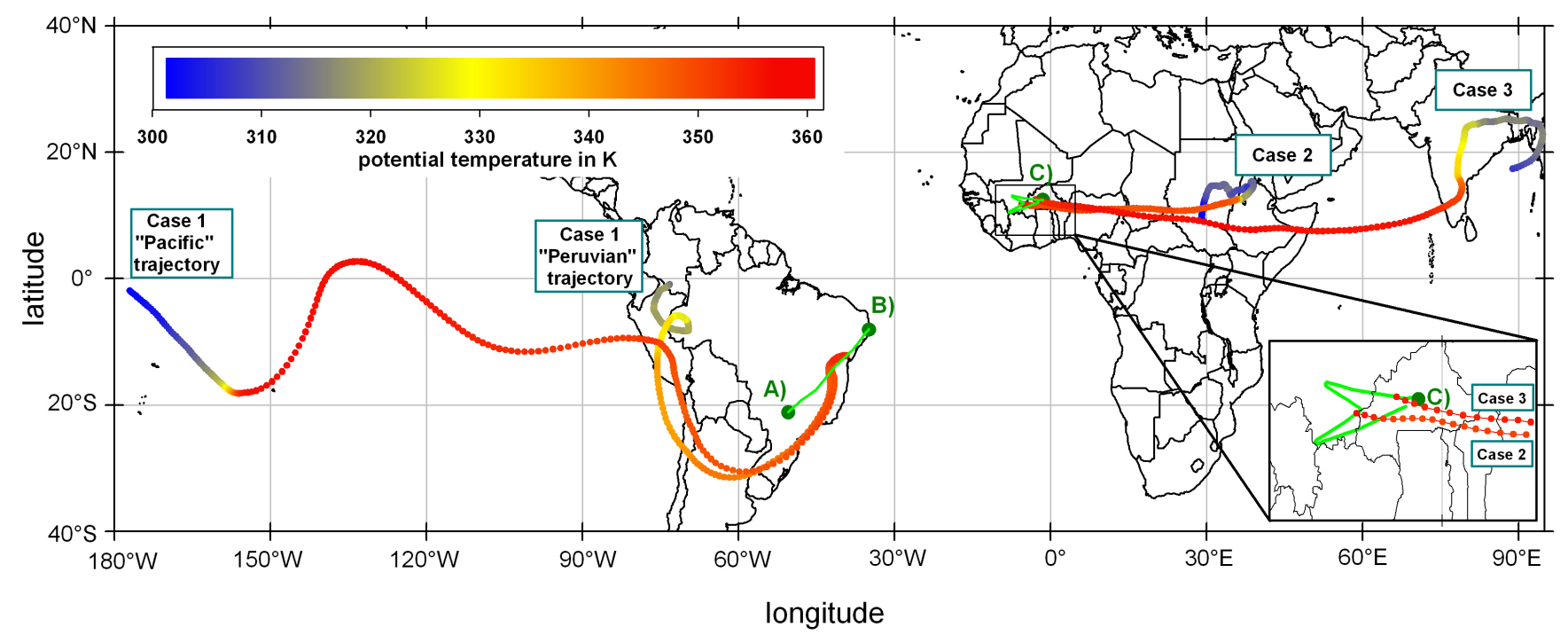

Fig. 6. Air mass trajectories for the NPF Cases 1-3 from different source regions intersecting the M-55 Geophysica flight tracks (light green) between (A) Araçatuba and (B) Recife, Brazil (Case 1, TROCCINOX) and during a local flight with departure and destination at (C) Ouagadougou, Burkina Faso (Case 2 and 3, SCOUT-AMMA) determined from FLEXTRA simulations. Trajectories are colored according to the potential temperature evolution along their pathways indicating vertical air mass movement. A close-up (bottom right) illustrates where the trajectories intersect with the SCOUT-AMMA flight track on 7 August 2006.

$50 \mathrm{pptv}$ and a pre-existing aerosol surface area of $4.0 \mu \mathrm{m}^{2}$ per $\mathrm{cm}^{3}$ are used then MAIA predicts extremely weak or absent NPF, resulting in negligible concentrations of nucleation mode aerosol at the times of COPAS measurement (dotted red lines in Fig. 7). The MAIA model predicts that both, neutral and charged nucleation, are taking place for the conditions studied. Therefore a discussion of the relative contributions from the neutral and ion-induced nucleation mechanism follows.

\subsubsection{Contribution of the ion-induced mechanism to the NPF simulated by MAIA}

The contributions of neutral and charged nucleation to new particle formation as simulated by MAIA on the FLEXTRA trajectories depend mainly on temperature and sulfuric acid concentration in the gas phase. In the UT, lower temperatures and high sulfuric acid gas phase concentrations, which may arise either due to low pre-existing aerosol concentrations, high initial $\mathrm{SO}_{2}$ levels, or both, favor neutral over charged nucleation, but the relative strengths of the two processes may change on a given trajectory along with environmental conditions. Therefore, no systematic bias towards either of the two nucleation processes exists on the considered trajectories, and either of the two processes may dominate depending on environmental conditions. For example, low temperatures (205-234 K) along the FLEXTRA trajectory leading from the Pacific Ocean to the Geophysica flight track during the TROCCINOX flight on 24 February 2005 (MAIA results in Fig. 7b) lead to stronger neutral nucleation at 500 pptv of $\mathrm{SO}_{2}$ over most of the trajectory. On the other hand, on the FLEXTRA trajectory originating in Peru, with somewhat higher temperatures (209-238 K), charged nucleation prevails at 500 pptv of $\mathrm{SO}_{2}$ over most of the trajectory (MAIA results in Fig. 7a). Figure 8 shows the simulated $\mathrm{H}_{2} \mathrm{SO}_{4}$ concentration and the fractional contribution of the ion-induced mechanism to the nucleation rate for the MAIA runs of Cases 1 through 4 (Fig. 7a-d). For illustration, the particle size distribution along one selected MAIA run (initialized with $50 \mathrm{pptv}$ of $\mathrm{SO}_{2}$ and $1.0 \mu \mathrm{m}^{2} \mathrm{~cm}^{-3}$ pre-existing aerosol surface area) is displayed for each of the cases. Generally, the highest nucleation rates result at the lowest preexisting aerosol surface and highest initial $\mathrm{SO}_{2}$ mixing ratio. The largest contribution of the ion-induced mechanism to the nucleation rate ranges at about $40-90 \%$ during the NPF bursts of Case 1 (Peruvian trajectory). The nucleation bursts display a characteristic 24-h periodicity in correlation with the solar zenith angle, which determines $\mathrm{OH}$ concentrations and $\mathrm{H}_{2} \mathrm{SO}_{4}$ production from the reaction of $\mathrm{SO}_{2}$ with $\mathrm{OH}$. In the MAIA simulations that were initialized with $500 \mathrm{pptv}$ of $\mathrm{SO}_{2}$, neither the ion-induced nor the neutral nucleation mechanism contributes to an increase of $N_{\mathrm{NM}}$ following the initial NPF burst. In the cases with 50 pptv of initial $\mathrm{SO}_{2}$, both mechanisms lead to a periodic increase of $N_{\mathrm{NM}}$, with a contribution by the ion-induced mechanism of at least $30 \%$ to $40 \%$. 


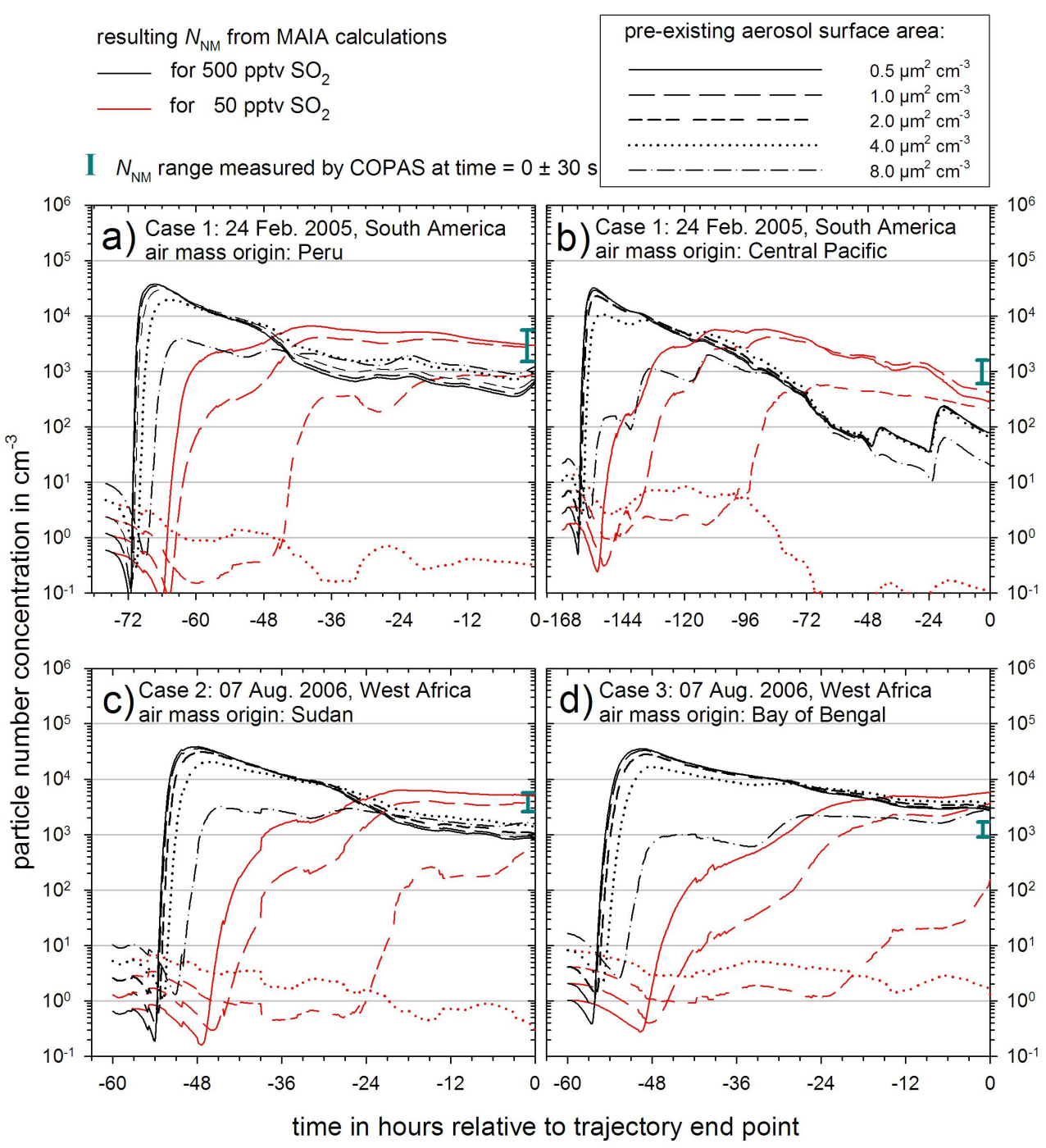

Fig. 7. Model calculation of particle number concentration, $N_{\mathrm{NM}}$, as measure for the strength of NPF caused by neutral and ion-induced binary aerosol nucleation of $\mathrm{H}_{2} \mathrm{SO}_{4}-\mathrm{H}_{2} \mathrm{O}$ droplets computed by the kinetic aerosol model MAIA (using FLEXTRA trajectories shown in Fig. 6). See text and Table 2 for details and model input parameters. Lines: $N_{\mathrm{NM}}$ produced by nucleation of $\mathrm{H}_{2} \mathrm{SO}_{4}$, oxidized from $\mathrm{SO}_{2}$, and $\mathrm{H}_{2} \mathrm{O}$ as function of time before the air parcel was sampled by the aircraft (at time $=0$ ) and as a function of pre-existing aerosol surface area. Black lines: assuming a pre-existing $\mathrm{SO}_{2}$ mixing ratio of 500 pptv. Red lines: for 50 pptv initial $\mathrm{SO}_{2}$. Green vertical bars: COPAS measurement of $N_{\mathrm{NM}}$ at time $=0$ (slightly displaced from $t=0$ for clarity).

\section{Discussion}

\subsubsection{Case 1 - 24 February 2005}

For Case 1 the MAIA calculation on the Peruvian trajectory (Fig. 7a) predicts number concentrations of nucleation mode particles ranging from $600-3000$ per $\mathrm{cm}^{3}$ at the intersection with the flight track. With the higher initial $\mathrm{SO}_{2}$ concentration (500 pptv), the concentration of nucleation mode aerosol $N_{\mathrm{NM}}$ peak early on the trajectory for all considered initial aerosol surface area concentrations (black curves in Fig. 7a). Following this peak, $N_{\mathrm{NM}}$ values gradually decrease due to coagulation of the particles, and due to their growth out of the size interval covered by $N_{\mathrm{NM}}$. At the time of the measurement, the simulations with 500 pptv of initial $\mathrm{SO}_{2}$ significantly underpredict the observed aerosol concentration, regardless of the initial aerosol surface area concentration.

With 50 pptv of initial $\mathrm{SO}_{2}$ (red curves in Fig. 7a), new particle formation is strongly suppressed at initial aerosol surface area concentrations $\geq 4 \mu \mathrm{m}^{2} \mathrm{~cm}^{-3}$. However, with decreasing initial aerosol surface area concentrations, NPF becomes more efficient, and for pre-existing aerosol surface area concentrations $\leq 1 \mu \mathrm{m}^{2} \mathrm{~cm}^{-3}, 50 \mathrm{pptv}$ of initial $\mathrm{SO}_{2}$ yields concentrations of nucleation mode aerosol at the time of the measurements that match the observations better than any of the 500 pptv runs. 


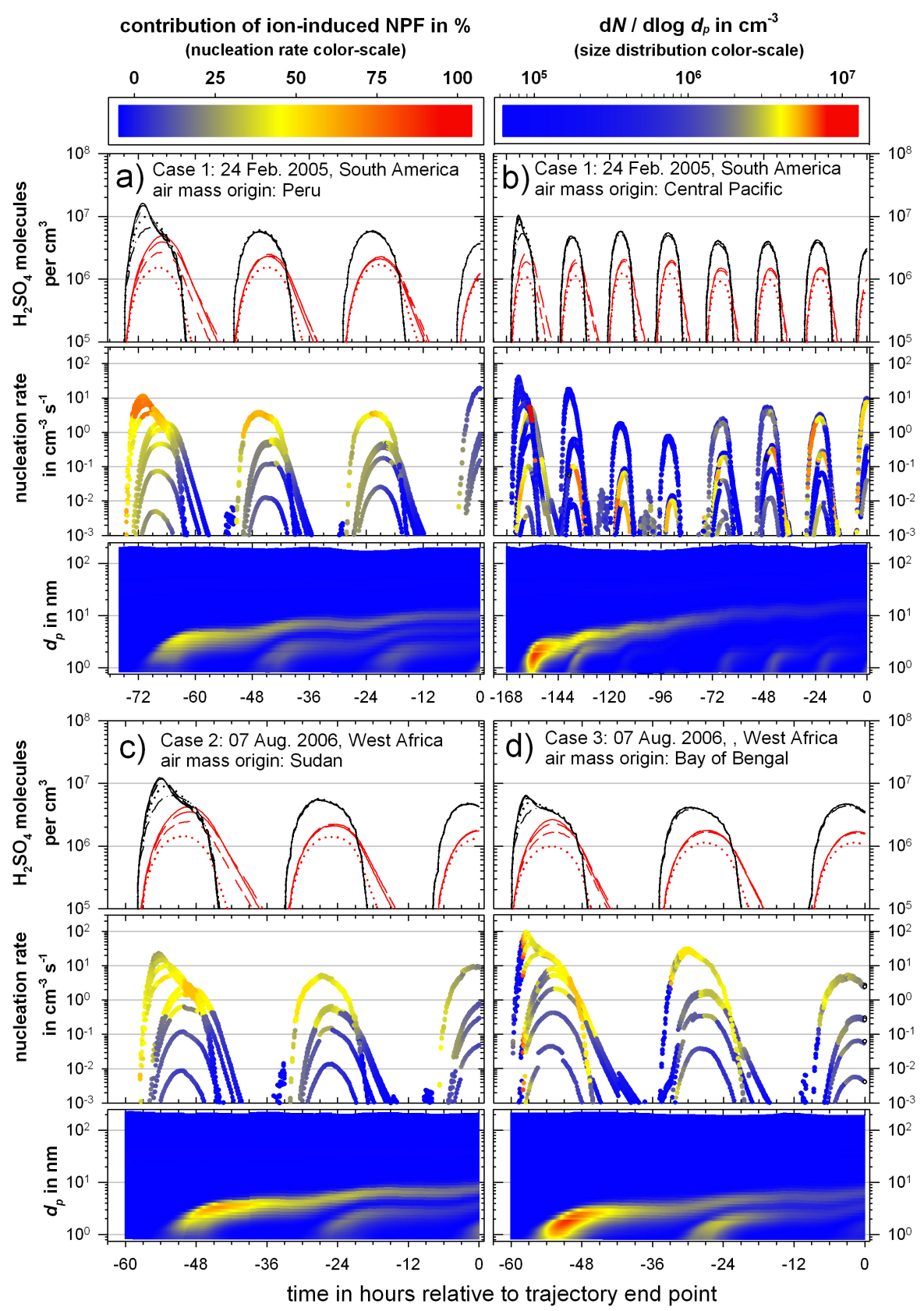

Fig. 8. $\mathrm{H}_{2} \mathrm{SO}_{4}$ concentration (top panels), nucleation rate (mid panels) and particles size distributions (bottom panels) for the Cases 1 through 4 simulated with MAIA (Fig. 7a-d). Color-coding and line style of the $\mathrm{H}_{2} \mathrm{SO}_{4}$ concentration curves follow the legend in Fig. 7. The nucleation rate is color-coded according to the fractional contribution of ion-induced NPF. Nucleation bursts occur with a 24-h periodicity, in correlation with the solar zenith angle, which determines $\mathrm{OH}$ concentrations and $\mathrm{H}_{2} \mathrm{SO}_{4}$ production from the reaction $\mathrm{SO}_{2}+\mathrm{OH}$ Particle

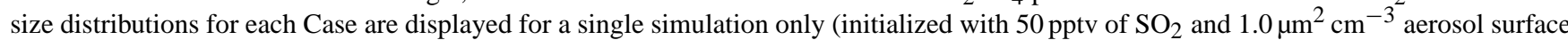
area).

Similar results are obtained on the trajectory arriving from the Pacific (Fig. 7b): here, however, more time has passed since the initial uplift compared to the Peruvian trajectory, and the newly formed particles have had more time to coagulate and grow out of the size interval covered by $N_{\mathrm{NM}}$ (cf.
Sect. 2.2). As a result, along this trajectory the model predicts particle concentrations that are significantly lower than the observations at the time of the measurement, as well as the concentrations produced on the Peruvian trajectory. 
The conclusions which can be drawn from these results are: the better match between modeled and observed $N_{\mathrm{NM}}$ from NPF is obtained with a low initial $\mathrm{SO}_{2}$. This indicates that in the considered cases, the observed $N_{\mathrm{NM}}$ is mainly governed by the pre-existing aerosol surface area rather than by $\mathrm{SO}_{2}$ mixing ratio. If the aerosol surface area is low enough (e.g. as a result of cloud processing) then a better agreement between the MAIA-simulated and the observed number density of nucleation mode particles is reached. While cloud processing reduces in different ways both, aerosol and $\mathrm{SO}_{2}$ concentrations, a reduction of aerosol surface area can more than compensate a reduction of $\mathrm{SO}_{2}$, and explain observed particle concentrations, as seen in the simulations. This is supported by the finding that high $\mathrm{SO}_{2}$ concentrations deteriorate the comparison of the simulations with the measurements. High $\mathrm{SO}_{2}$ concentrations lead to a rapid growth of the newly formed particles out of the nucleation mode particle size regime. Furthermore, the better match between measured and modeled $N_{\mathrm{NM}}$ is obtained for the Peruvian trajectory, compared to the Pacific trajectory. This may indicate that NPF, which resulted in the observed concentration of nucleation mode aerosol, most likely occurred in air parcels originating from Peru.

\subsection{Case 2 - 7 August 2006}

For the NPF Case 2 (Fig. 7c), MAIA reproduces the COPAS nucleation mode particle measurement quite well with $N_{\mathrm{NM}}$ around 4000 particles per $\mathrm{cm}^{3}$, provided that the lower initial $\mathrm{SO}_{2}$ mixing ratio of $50 \mathrm{pptv}$ and a very low initial aerosol surface area concentration $\left(\leq 1 \mu \mathrm{m}^{2} \mathrm{~cm}^{-3}\right)$ are assumed. Higher aerosol surface areas or a high initial $\mathrm{SO}_{2}$ mixing ratio give lower simulated particle concentrations at the time of the measurement. This is indicative of efficient cloud processing along the trajectory, e.g. in deep convection. Given the FLEXPART prediction of $1.4 \mathrm{ppbv} \mathrm{SO}_{2}$ for this trajectory (cf. Fig. 5b at 14:15 UTC), efficient cloud processing appears very likely if the $\mathrm{SO}_{2}$ is to be reduced to values around 50 pptv. Again, uncertainties in the EDGAR inventory and the unquantified losses and dilution of $\mathrm{SO}_{2}$ due to cloud related processes and mixing with background air in the TTL may well be the cause of the corresponding differences.

\subsection{Case 3 - 7 August 2006}

The predicted number densities of nucleation mode particles for NPF Case 3 (Fig. 7d) range between 3000-4000 particles per $\mathrm{cm}^{3}$ for the simulations with initial $\mathrm{SO}_{2}$ concentrations of $500 \mathrm{pptv}$, and exceed the value of 1300 per $\mathrm{cm}^{3}$ determined by COPAS. For $50 \mathrm{pptv} \mathrm{SO}_{2}$ and $\leq 1 \mu \mathrm{m}^{2} \mathrm{~cm}^{-3}$ of pre-existing aerosol surface area, the MAIA results coincide with those from the runs with 500 pptv. At 50 pptv initial $\mathrm{SO}_{2}$ concentration and $0.5 \mu \mathrm{m}^{2} \mathrm{~cm}^{-3}$ pre-existing aerosol surface area, the model predicts a significantly higher particle concentration, while for aerosol surface area $>1 \mu \mathrm{m}^{2} \mathrm{~cm}^{-3}$,
$N_{\text {NM }}$ remains low with values $\sim 100 \mathrm{~cm}^{-3}$ or below. Thus, a low $\mathrm{SO}_{2}$ mixing ratio ( $\leq 50 \mathrm{pptv}$ ) and only a narrow range of pre-existing aerosol surface area (between $1-2 \mu \mathrm{m}^{2} \mathrm{~cm}^{-3}$ ) seem to be the preconditions for predicting the number concentration of nucleation mode particles with MAIA in the order of magnitude as observed by in-situ measurements.

\subsection{Case study upshot}

Generally, the number concentrations of nucleation mode particles predicted by the MAIA nucleation model compare well with the $N_{\mathrm{NM}}$ measured by COPAS during observed NPF events. The remaining differences between the model predictions and the observations may be due to:

1. the uncertainty of the air mass trajectory calculations by the FLEXTRA model, particularly the uncertainties in the representation of (local) convection,

2. the uncertainties in the source strengths for $\mathrm{SO}_{2}$,

3. for NPF Case 3 the unquantified losses of $\mathrm{SO}_{2}$ inside clouds (which may play a significant role given in the very large MCS that were regularly present during the West African monsoon season of the year 2006),

4. the uncertainties in the MAIA model assumptions by neglecting air mass mixing/dilution and $\mathrm{SO}_{2}$ processing or

5. the contribution of nucleating and condensable species not accounted for by MAIA, such as organic compounds (Heald et al., 2005; Kulmala et al., 2006; Ekman et al., 2008).

6. a growing probability, with increasing time span covered by a MAIA run (i.e. up to 6.5 days for one of the case studies shown herein) that nucleation mode particle numbers at the end of the trajectories are unrealistically high, considering that in reality the formation of clouds (even at very high altitudes in the tropics) and interaction of those with the newly formed particles becomes likely with time.

Nevertheless, the results suggest that a low pre-existing aerosol surface area is an essential prerequisite for NPF in the tropical UT.

The MAIA nucleation model simulations concerning these NPF cases were based on assumptions of initial $\mathrm{SO}_{2}$ concentration and preexisting aerosol surface area, and account only for nucleation of $\mathrm{H}_{2} \mathrm{SO}_{4}-\mathrm{H}_{2} \mathrm{O}$ aerosol particles. These assumptions lead to MAIA predictions of the number of nucleation mode particles mostly in reasonable agreement with in situ observation without considering a nucleation mechanism involving organic components.

However, in Fig. 9 the $N_{\mathrm{NM}}$ is displayed versus the CO mixing ratio measured during the flight on 7 August 2006 over West Africa. Data points are color-coded according to 


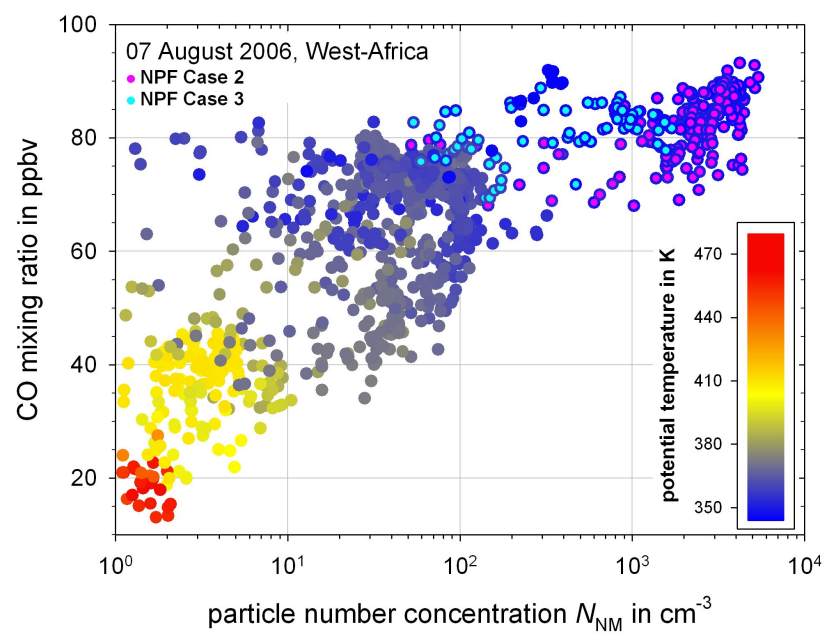

Fig. 9. Carbon monoxide (CO) mixing ratio (from the COLD instrument) versus particle number concentration $N_{\mathrm{NM}}$ measured by COPAS during the flight on 7 August 2006 (SCOUT-AMMA). The data points are colored according to the potential temperature (ignoring measurements with $N_{\mathrm{NM}}<1 \mathrm{~cm}^{-3}$ ). The COPAS samples of NPF Case 2 (pink) and NPF Case 3 (cyan) are highlighted. The maximum $\mathrm{CO}$ mixing ratios suggest air masses originating from anthropogenic emissions in Asia (for details see text or Law et al., 2010).

the potential temperature. Those $N_{\mathrm{NM}}$ which were measured during NPF Case 2 and Case 3 are highlighted separately. $\mathrm{CO}$ mixing ratios with more than 60 ppbv were generally observed below $380 \mathrm{~K}$ potential temperature which is below the cold point tropopause. Generally, the occurrence of NPF events with $N_{\mathrm{NM}}$ of more than $\sim 100$ particles per $\mathrm{cm}^{3}$ is accompanied by $\mathrm{CO}$ mixing ratio in excess of $\sim 70 \mathrm{ppbv}$ (typical CO background levels are 60-70 ppbv in the pristine marine boundary layer). In particular, high number concentrations of nucleation mode particles $\left(N_{\mathrm{NM}}\right.$ of more than 2000 particles per $\mathrm{cm}^{3}$ ) occur when the analyzed air masses are $\mathrm{CO}$ enriched ( $>85 \mathrm{ppbv}$ of $\mathrm{CO}$ ) at $350 \mathrm{~K}<\Theta<360 \mathrm{~K}$.

Law et al. (2010) identified air masses containing elevated $\mathrm{CO}$ (concurrently with $\mathrm{O}_{3}, \mathrm{CO}_{2}$, and $\mathrm{NO}_{\mathrm{y}}$ ) which were influenced by pollution emissions over Asia and India before undergoing long range transport towards the TTL over West Africa. Accordingly, Law et al. (2010) estimates, that 40\% of the air masses reaching the $355 \mathrm{~K}$ level over West Africa during SCOUT-AMMA ( $\sim 20 \%$ at the $370 \mathrm{~K}$ level) had been impacted by pollution. Such air may contain compounds such as $\mathrm{SO}_{2}$ and gaseous organic substances as well as organic aerosols (Lelieveld et al., 2001). Therefore, it cannot be excluded that nucleation of organic compounds contributed to the observed NPF. More detailed conclusions, particularly concerning specific organic species which probably influence the NPF in the TTL region, or if, as Kulmala et al. (2006) suggest, the nucleation mechanism of organic compounds are dominant, cannot be reached here because of a the lack of adequate instrumentation on the Geophysica.



Fig. 10. Cloud particle size distributions as function of particle diameter, $d_{\mathrm{p}}$, measured by the FSSP-100 (24 February 2005), and the combination of FSSP-100 with Cloud Imaging Probe (CIP, 7 August 2006). Vertical error bars: uncertainties of the instruments detection volumes and due to counting statistics. Horizontal bars: Particle size bin width. Cases as defined in previous figures. Case 1: upper tropospheric cirrus. Case 2: cirrus cloud related to recent convection (but not necessarily related to Mososcale Convective System (MCS) outflow). Case 3: anvil of a West African monsoon MCS.

\subsection{NPF inside clouds}

\subsubsection{In-cloud $N_{\mathrm{NM}}$ features over Brazil (Case 1)}

During the TROCCINOX NPF Case 1 the nucleation mode particles almost disappeared $\left(N_{\mathrm{NM}}\right.$ as low as $\left.40 \mathrm{~cm}^{-3}\right)$ when the aircraft flew in a cirrus cloud (as indicated by the FSSP100 data for $N_{>2} \mu \mathrm{m}$ in Fig. 4a) between 14:13:20 and 14:16:40 UTC. The number concentration of ice particles with $d_{\mathrm{p}}>2 \mu \mathrm{m}$ reached up to $1.1 \mathrm{~cm}^{-3}\left(0.1 \mathrm{~cm}^{-3}\right.$ on average) and the cloud particle size distribution is given in Fig. 10 by the light green curve (Note: the CIP was not operated during TROCCINOX). More details for Case 1 are provided in Table 3. The particle surface area of the cirrus cloud over South America is significantly smaller compared to observations over West Africa. This is likely due to instrumental differences for Case 1 the particle surface area was exclusively obtained from FSSP-100. Thus, particles larger than the upper size limit of the instrument (i.e. $d_{\mathrm{p}}>30 \mu \mathrm{m}$ ) could not be detected even though they probably were present. Judging from the shape of the size distribution in Fig. 10, however, it is plausible that the number densities of the larger ice particles in Case 1 were significantly below those of the other clouds, and hence that the total ice surface area observed over South America was indeed lower than over West Africa. 
Table 3. Ice cloud microphysical parameters for the cloud events during NPF observation measured on board the M-55 Geophysica by the FSSP-100 and the CIP as well as the cloud particle volume backscatter coefficient and depolarization measured by the MAS instrument (SCOUT-AMMA). Note that the last column refers to the cloud parameters when nucleation mode particles fully disappear.

\begin{tabular}{|c|c|c|c|c|c|}
\hline & $\begin{array}{l}\text { South } \\
\text { America }\end{array}$ & \multicolumn{4}{|c|}{ West Africa } \\
\hline & $\begin{array}{r}\text { NPF } \\
\text { Case } 1\end{array}$ & $\begin{array}{l}\text { NPF Case 2, } \\
\text { Ice-cloud I }\end{array}$ & $\begin{array}{l}\text { NPF Case 3, } \\
\text { Ice-cloud II }\end{array}$ & $\begin{array}{l}\text { NPF Case 3, } \\
\text { Ice-cloud III }\end{array}$ & $\begin{array}{r}\quad N_{\mathrm{NM}}=0 \\
\text { Ice-cloud III }\end{array}$ \\
\hline averaging time in $\mathrm{s}$ & 262 & 98 & 83 & 20 & 2 \\
\hline covered flight distance in $\mathrm{km}$ & 35.3 & 12.7 & 11.8 & 2.8 & 0,2 \\
\hline altitude in $\mathrm{km}$ & 13 & 12.2 & 12.6 & 12.5 & 11.9 \\
\hline potential temperature in $\mathrm{K}$ & 351 & 349 & 350 & 348 & 350 \\
\hline$N_{\mathrm{NM}}$ in $\mathrm{cm}^{-3}$ & $260-7700$ & $650-4000$ & $<1300$ & $<750$ & $\approx 0$ \\
\hline \multicolumn{6}{|l|}{ ice cloud particle properties } \\
\hline $\begin{array}{l}\text { averaged number } \\
\text { concentration in } \mathrm{cm}^{-3}\end{array}$ & 0.1 & 0.4 & 0.3 & 0.3 & 4.4 \\
\hline surface area in $\mu \mathrm{m}^{2} \mathrm{~cm}^{-3}$ & 52.2 & $3.5 \times 10^{6}$ & $7.9 \times 10^{5}$ & $3.4 \times 10^{6}$ & $2.6 \times 10^{7}$ \\
\hline for $d_{\mathrm{p}}$ range in $\mu \mathrm{m}$ & $2.7-29.7$ & $2.7-1600$ & $2.7-1600$ & $2.7-1600$ & $2.7-1600$ \\
\hline $\begin{array}{l}\text { averaged aerosol volume backscatter } \\
\text { coeff. in } \mathrm{m}^{-1} \mathrm{sr}^{-1}\end{array}$ & - & $(1.6 \pm 1) \times 10^{6}$ & $(1.6 \pm 1) \times 10^{6}$ & $(3.8 \pm 3) \times 10^{6}$ & $12 \times 10^{6}$ \\
\hline $\begin{array}{l}\text { averaged aerosol volume } \\
\text { depolarization in \% }\end{array}$ & - & $62 \pm 6$ & $58 \pm 4$ & $59 \pm 5$ & 78 \\
\hline
\end{tabular}

\subsubsection{In-cloud $N_{\mathrm{NM}}$ features over West Africa (Cases 2 and 3)}

Figure 11 shows a close-up of the time series of the SCOUTAMMA NPF Cases 2 and 3, and corresponding cloud particle size distributions are shown in Fig. 10. In Case 2 the Geophysica crossed a thin cirrus layer (labeled as Ice-cloud I in Fig. 11) at $~ 12.5 \mathrm{~km}$ altitude (14:12:18-14:13:31 UTC) with average ice particle concentrations of $0.4 \mathrm{~cm}^{-3}$, a maximum number density of $1.3 \mathrm{~cm}^{-3}$, particle surface areas around $3.5 \times 10^{6} \mu \mathrm{m} \mathrm{cm}^{-3}$ and an aerosol volume backscatter coefficient of $1.6 \times 10^{-6} \mathrm{~m}^{-1} \mathrm{sr}^{-1}$ with depolarization of $62 \%$ (cf. Fig. 4b, Table 3, and black curve in Fig. 11). The highest $N_{\mathrm{NM}}$ in this cloud ranged up to 4000 particles per $\mathrm{cm}^{3}$. During NPF Case 3 two cirrus clouds were encountered in connection with the anvil outflow of a West African MCS (as described in detail by Frey et al., 2011). First, a thin cirrus layer was passed at $\sim 13 \mathrm{~km}$ altitude (15:36:0915:37:32, marked as Ice-cloud II) with ice particle concentrations up to $0.9 \mathrm{~cm}^{-3}$, at $0.3 \mathrm{~cm}^{-3}$ on average. A denser cirrus cloud was crossed at $\sim 12 \mathrm{~km}$ altitude (15:38:00-15:42:36, denoted with Ice-cloud III), where $N_{>2 \mu \mathrm{m}}$ of up to $8.3 \mathrm{~cm}^{-3}$ $\left(4.4 \mathrm{~cm}^{-3}\right.$ in average) was detected by the FSSP-100 (cf. Fig. 4b). At the time when the maximum cloud particle concentration in Ice-cloud II was detected, $N_{\mathrm{NM}}$ still ranged between 1100 and 630 particles per $\mathrm{cm}^{3}$. For Ice-cloud III a size distribution is reported from the cloud edge region (blue curve in Fig. 10). Here, $N_{\mathrm{NM}}$ was still about 760 particles per $\mathrm{cm}^{3}$. Well inside Ice-cloud III, the nucleation mode particles vanished and $N_{\mathrm{NM}}$ decreased to zero (Fig. 11). Notably, the ice particle size distribution $d N / d \log d_{\mathrm{p}}$ (dark cyan curve in Fig. 10) exhibits the highest values encountered during SCOUT-AMMA. At the same time, the aerosol volume backscatter coefficient as well as the cloud particle volume depolarization increased significantly. After exiting Icecloud III, $N_{\mathrm{NM}}$ recovered to concentrations between 1701500 nucleation mode particles per $\mathrm{cm}^{3}$ (Fig. 11).

\subsubsection{In-cloud $N_{\mathrm{NM}}$ features over Australia}

During 6 of 8 local flights of the SCOUT-O 3 mission enhanced number concentration of nucleation mode particles were observed together with cloud particles. In Fig. 12 the data of $N_{\mathrm{NM}}$ (from measurements during $\mathrm{SCOUT}_{3} \mathrm{O}_{3}$ and SCOUT-AMMA) that fulfill the NPF criterion are shown versus the $N_{>2} \mu \mathrm{m}$ (size range $2.7 \mu \mathrm{m}<d_{\mathrm{p}}<1.4 \mathrm{~mm}$, from FSSP-100 and CIP measurements). Generally, nucleation mode particles are observed with up to 4000 particles per $\mathrm{cm}^{3}$ when cloud particles are present. As long as $N_{>2} \mu \mathrm{m}$ remains smaller than 2 particles per $\mathrm{cm}^{3}$ the $N_{\mathrm{NM}}$ seems to be independent on the number density of cloud elements. The altitude range where the coexistence of nucleation mode and cloud particles is mainly observed is coincident with the level where NPF was found to occur extensively in the absence of 


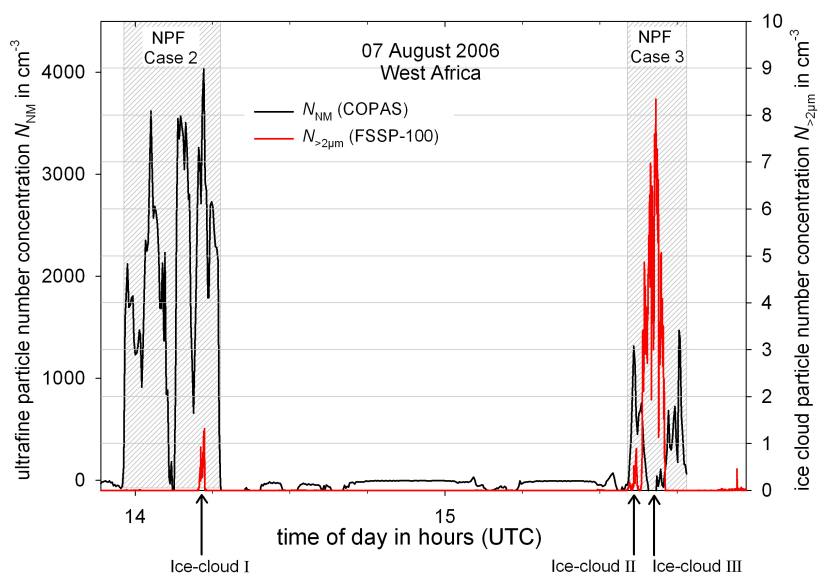

Fig. 11. Close-up of the time series of measured number concentration of nucleation mode particles $N_{\mathrm{NM}}$ (COPAS, black line) and of ice cloud particles $N_{>2} \mu \mathrm{m}$ (FSSP-100, red line) of the M-55 Geophysica flight on 7 August 2006 over West Africa. Nucleation mode particles are present at $170-1000 \mathrm{~cm}^{-3}$ in ice clouds $\left(1.3-0.9 \mathrm{~cm}^{-3}\right.$, ice cloud I and II). At ice particle concentrations above $2 \mathrm{~cm}^{-3}$ NPF mode particles were not detected (Ice-cloud III).

cloud particles (i.e. 340-380 K). This observation does neither prove nor exclude whether the nucleation mode particles were formed in the cloud or if the nucleation mode particles are remnants of NPF that occurred prior to cloud formation. Furthermore, no NPF event was observed along with $N_{>2} \mu \mathrm{m}$ exceeding $2 \mathrm{~cm}^{-3}$.

\subsubsection{Intercomparison and interpretation}

The cloud particle size distributions during the in-cloud NPF cases are very similar for Ice-clouds I and II, as well as for the edge region of Ice-cloud III. The measurements of the MAS instrument suggest that the aerosol volume backscatter coefficient as well as the depolarization remains nearly constant for Ice-cloud I, II, and the edge of Ice-cloud III, which indicates that the particle shape (crystal habit) and cloud element sizes did not significantly change from one ice cloud to the other. However, deeper inside Ice-cloud III, with high ice crystal surface area concentrations, $N_{\mathrm{NM}}$ values were significantly reduced compared to the other ice clouds.

The occurrence of nucleation mode aerosol particles inside cirrus clouds has been previously reported by Lee et al. (2004). Kazil et al. (2007) have shown that aerosol nucleation inside cirrus clouds is possible and more viable at small ice and aerosol surface area concentrations. Alternatively, nucleation mode aerosol particles inside cirrus clouds could arise due to aerosol nucleation in cloud-free air and subsequent cirrus formation, by sedimentation of cirrus ice crystals into an air mass in which NPF occurred, or by turbulent mixing of air parcels that contain nucleation mode aerosol and ice crystals. From our observations in West Africa it can be concluded that in the presence of ice cloud particles



Fig. 12. NPF events observed during the $\mathrm{SCOUT}_{-} \mathrm{O}_{3}$ and the SCOUT-AMMA missions (Australia 2005 and West Africa 2006, respectively) when simultaneously cloud elements were detected. NPF can be observed only if cloud particle number concentrations (from FSSP-100 and CIP measurements with $2.7 \mu \mathrm{m}<d_{\mathrm{p}}<1.4 \mathrm{~mm}$ ) remain below 2 particles per $\mathrm{cm}^{3}$.

$\left(d_{\mathrm{p}}>2 \mu \mathrm{m}\right)$ at concentrations of $\sim 2 \mathrm{~cm}^{-3}$ or less, nucleation mode particles can form or persist in significant amounts. This upper limit for the cloud particle concentration is supported by the comparison of $N_{\mathrm{NM}}$ of all NPF events with $N_{>2 \mu \mathrm{m}}$ from the measurements over West Africa (SCOUTAMMA, 2006) and Australia (SCOUT-O 3,2005$)$ when simultaneously cloud particles where observed (Fig. 12). Additionally, Fig. 12 shows that the coexistence of nucleation mode particles with cloud elements is observed frequently. However, the NPF Case 1, observed over South America, also demonstrates that the presence of cirrus clouds with much lower ice particle concentrations suppresses the formation or presence of nucleation mode aerosol. Uncovering the mechanisms giving rise to the presence and possibly to the formation of nucleation mode aerosol particles inside cirrus clouds will require detailed measurements of gas phase composition, and of aerosol and ice particle size distributions in and around cirrus.

\section{Summary and conclusions}

Abundances of nucleation mode aerosol, indicative for recent new particle formation, were observed by aircraft-borne in situ measurements in the tropical continental free troposphere and TTL region over Brazil, Central America, West Africa and Australia. Number concentrations of these particles as high as $7700 \mathrm{~cm}^{-3}$ were measured at $\sim 12.5 \mathrm{~km}$ altitude over South America (24 February 2005) and up to 
$4000 \mathrm{~cm}^{-3}$ at $\sim 13.0 \mathrm{~km}$ over West Africa (7 August 2006). One NPF event observed at $\sim 13.7 \mathrm{~km}$ over South America even peaks to $>16000$ nucleation mode particles per $\mathrm{cm}^{3}$ (27 January 2005). New particle formation, which was observed on half of all flights over South America and during each local flight over West Africa, was confined to a layer between $340 \mathrm{~K}$ and $370 \mathrm{~K}$ potential temperature. This potential temperature range covers the tropical upper troposphere (UT) and the Tropical Transition Layer (TTL). This potential temperature (altitude) range is co-located with that of the tropical convection outflow, which appears responsible for the observed nucleation mode particles. Here, the conditions (high concentration of NPF precursor gases, air which is nearly free of aerosols due to in-cloud scavenging, and low ambient temperatures) seem to be most favorable for NPF. Except for one case, no intensive new particle formation was encountered in the stratosphere. The nucleation mode particles were predominantly volatile $(>75 \%)$ when heated to $250{ }^{\circ} \mathrm{C}$ during sampling. The sampling of particles after heat exposure primarily aims at vaporizing $\mathrm{H}_{2} \mathrm{SO}_{4}-\mathrm{H}_{2} \mathrm{O}$ aerosol compounds, but aerosol compounds of higher volatility (e.g. organics) would vaporize as well. The highest amounts of newly formed particles and the longest duration of NPF events in the UT/TTL were found between $350-370 \mathrm{~K}$ potential temperature over Brazil and West Africa. This indicates - refining the conclusions of Borrmann et al. (2010) that NPF is strongest above the convective outflow regions of the upper troposphere and in the lowest part of the TTL. This comparably thin layer appears as the region of origin of the nucleation mode particles; a result that narrows down the findings of Brock et al. (1995) who identified earlier the TTL, in general, as a source of stratospheric background aerosol.

FLEXPART backward trajectory calculations connect regions of elevated $\mathrm{SO}_{2}$ emissions with locations at which nucleation mode particles were detected. Simulations with the MAIA aerosol model along the trajectories, initialized with $\mathrm{SO}_{2}$ levels that are consistent with a significant depletion of the $\mathrm{SO}_{2}$, e.g. by aqueous chemistry, show that neutral and charged nucleation of $\mathrm{H}_{2} \mathrm{SO}_{4}$ and $\mathrm{H}_{2} \mathrm{O}$ can explain the observed $N_{\mathrm{NM}}$. As nucleation mode particles from strong, burst-like events of NPF (due to high $\mathrm{SO}_{2}$ loading) rapidly coagulate and grow, the MAIA simulations based on small amounts of $\mathrm{SO}_{2}$ predict slower but longer lasting formation of new nucleation mode particles, as a function of time, in similar or even higher quantities. However, a contribution of other nucleation mechanisms cannot be excluded. The measurements over West Africa exhibit elevated concentrations of CO during NPF events, possibly associated with anthropogenic emissions from Asia.

Nucleation mode particles were detected not only in clear air but also within thin cirrus cloud layers. Mixing of cloudfree and cloudy air parcels, aerosol nucleation and cirrus formation occurring in sequence, and ice particles which have sedimented into an air parcel where aerosol nucleation has occurred could explain the observation of nucleation mode aerosol inside cirrus clouds. Nucleation mode aerosol particles were found at concentrations of up to 4000 particles per $\mathrm{cm}^{3}$ inside cirrus cloud segments where the total number concentration of cloud particles (within a size range of $2.7 \mu \mathrm{m}<d_{\mathrm{p}}<1.6 \mathrm{~mm}$ ) did not exceed $2 \mathrm{~cm}^{-3}$. Considering that this in-cloud observation occurred in the convective outflow region and, thus, in proximity of a tropical convective cell (cf. Frey et al., 2011), in-cloud (cirrus) NPF in the tropical UT is conceivable, if sufficient amounts of NPF precursors are carried aloft by deep convection from the boundary layer. Despite significant removal of the gaseous precursors by scavenging during the upward transport, enough gaseous material may remain inside the $\mathrm{Cb}$ anvil and its outflow to enable NPF.

If NPF occurs, as our data seem to indicate, in a remarkably narrow altitude range at the bottom of the TTL, then the outflows of $\mathrm{Cb}$ clouds and MCS may turn out to be a major driver of NPF in the TTL by supplying NPF precursor substances from the boundary layer. This would strengthen the role of the UT and bottom TTL as source region for the stratospheric aerosol population, and highlights the question to what extent NPF precursor substances from the boundary layer-possibly of anthropogenic origin - affect stratospheric aerosol concentrations and cirrus formation in the bottom TTL.

Acknowledgements. The TROCCINOX and $\mathrm{SCOUT}^{-\mathrm{O}_{3}}$ projects were funded by the EC under Contracts No. EVK2-CT-2001-00122 and 505390-GOCE-CT-2004-505390. The M-55 Geophysica campaigns also were supported by the EEIG-Geophysica Consortium, CNRS-INSU, EC Integrated Projects AMMA-EU (Contract No. 004089-2), and by the DLR. Based on a French initiative, AMMA was funded by several research agencies from France, the United Kingdom, the United States, Africa, Germany, and in particular from the European Community Sixth Framework Program (AMMA-EU). For us significant support also was provided from the Max-Planck-Society. Also we acknowledge logistical support from the AMMA Operations Centre in Niamey, Niger. The local authorities, scientists, and staff in Araçatuba (Brazil), Darwin (Australia) and Ouagadougou (Burkina Faso) were extraordinarily helpful for conducting the campaigns. We thank T. Drabo (Ouagadougou), S. Balestri and the entire Geophysica crew, especially the pilots and engineers. Essential technical support for our instruments was provided by T. Böttger, W. Schneider, C. von Glahn, and M. Flanz, and is most gratefully acknowledged. H. Rüba, T. Hamburger and B. Weinzierl are acknowledged for supporting the CPC measurements aboard the DLR Falcon-20. We thank U. Schumann (DLR) for the coordination and the flight planning during TROCCINOX. J. Kazil is supported by the NOAA OAR Climate Program Office grant NA08OAR4310566. The flight missions of the NASA WB-57F aircraft (Pre-AVE, AVE_0506, Cr-AVE and TC4) in the years 2004 to 2007 during which the University of Denver NMASS-FCAS instrument participated have been supported by the NASA Earth Science Division.

Edited by: V.-M. Kerminen 


\section{References}

Arnold, F., Schneider, J., Gollinger, K., Schlager, H., Schulte, P.,Hagen, D. E.,Whitefield, P. D., Velthoven, P. v., Observation of upper tropospheric sulfur dioxide- and acetone-pollution: Potential implications for hydroxyl radical and aerosol formation, Geophys. Res. Lett., 24, 57-60, doi:10.1029/96GL03693, 1997.

Barth, M. C., Stuart, A. L., and Skamarock, W. C.: Numerical simulations of the July 10, 1996, Stratospheric-Tropospheric Experiment: Radiation, Aerosols, and Ozone (STEREAO)-Deep Convection experiment storm: Redistribution of soluble tracers, J. Geophys. Res., 106, 12381-12400, 2001.

Borrmann, S., Kunkel, D., Weigel, R., Minikin, A., Deshler, T., Wilson, J. C., Curtius, J., Volk, C. M., Homan, C. D., Ulanovsky, A., Ravegnani, F., Viciani, S., Shur, G. N., Belyaev, G. V., Law, K. S., and Cairo, F.: Aerosols in the tropical and subtropical UT/LS: in-situ measurements of submicron particle abundance and volatility, Atmos. Chem. Phys., 10, 5573-5592, doi:10.5194/acp-10-5573-2010, 2010.

Brock, C. A., Hamill, P., Wilson, J. C., Jonsson, H. H., and Chan, K. R.: Particle Formation in the Upper Tropical Troposphere a Source of Nuclei for the Stratospheric Aerosol, Science, 270, 1650-1653, 1995.

Brock, C. A., Schröder, F., Kärcher, B., Petzold, A., Busen, R., and Fiebig, M.: Ultrafine particle size distributions measured in aircraft exhaust plumes, J. Geophys. Res.-Atmos., 105, 2655526567, 2000.

Brown, P. N., Byrne, G. D., and Hindmarsh, A. C.: VODE, A Variable-Coefficient ODE Solver, SIAM J. Sci. Stat. Comput., 10, 1038-1051, 1989.

Brunner, D., Siegmund, P., May, P. T., Chappel, L., Schiller, C., Müller, R., Peter, T., Fueglistaler, S., MacKenzie, A. R., Fix, A., Schlager, H., Allen, G., Fjaeraa, A. M., Streibel, M., and Harris, N. R. P.: The SCOUT-O3 Darwin Aircraft Campaign: rationale and meteorology, Atmos. Chem. Phys., 9, 93-117, doi:10.5194/acp-9-93-2009, 2009.

Buontempo, C., Cairo, F., Di Donfrancesco, G., Morbidini, R., Viterbini, M., and Adriani, A.: Optical measurements of atmospheric particles from airborne platforms: in situ and remote sensing instruments for balloons and aircrafts, Ann. Geophys.Italy, 49, 57-64, 2006.

Cairo, F., Pommereau, J. P., Law, K. S., Schlager, H., Garnier, A., Fierli, F., Ern, M., Streibel, M., Arabas, S., Borrmann, S., Berthelier, J. J., Blom, C., Christensen, T., D’Amato, F., Di Donfrancesco, G., Deshler, T., Diedhiou, A., Durry, G., Engelsen, O., Goutail, F., Harris, N. R. P., Kerstel, E. R. T., Khaykin, S., Konopka, P., Kylling, A., Larsen, N., Lebel, T., Liu, X., MacKenzie, A. R., Nielsen, J., Oulanowski, A., Parker, D. J., Pelon, J., Polcher, J., Pyle, J. A., Ravegnani, F., Rivière, E. D., Robinson, A. D., Rckmann, T., Schiller, C., Simões, F., Stefanutti, L., Stroh, F., Some, L., Siegmund, P., Sitnikov, N., Vernier, J. P., Volk, C. M., Voigt, C., von Hobe, M., Viciani, S., and Yushkov, V.: An introduction to the SCOUT-AMMA stratospheric aircraft, balloons and sondes campaign in West Africa, August 2006: rationale and roadmap, Atmos. Chem. Phys., 10, 2237-2256, doi:10.5194/acp10-2237-2010, 2010a.

Cairo, F., Di Donfrancesco, G., Snels, M., Fierli, F., Viterbini, M., Borrmann, S., and Frey, W.: A comparison of light backscattering and particle size distribution measurements in tropical cirrus clouds, Atmos. Meas. Tech., 4, 557-570, doi:10.5194/amt-4-
557-2011, 2011 b.

Carmichael, G. R., Ferm, M., Thongboonchoo, N., Woo, J.-H., Chan, L. Y., Murano, K., Viet, P. H., Mossberg, C., Bala, R., Boonjawat, J., Upatum, P., Mohan, M., Adhikary, S. P., Shrestha, A. B., Pienaar, J. J., Brunke, E. B., Chen, T., Jie, T., Guoan, D., Peng, L. C., Dhiharto, S., Harjanto, H., Jose, A. M., Kimani, W., Kirouane, A., Lacaux, J.-P., Richard, S., Barturen, O., Cerda, J. C., Athayde, A., Tavares, T., Cotrina, J. S., and Bilici, E.: Measurements of sulfur dioxide,ozone and ammonia concentrations in Asia, Africa, and South America using passive samplers, Atmos. Environ., 37, 1293-1308, doi:10.1016/S13522310(02)01009-9, 2003.

Carn, S. A., Krueger, A. J., Krotkov, N. A., Yang, K., and Levelt, P. F.: Sulfur dioxide emissions from Peruvian copper smelters detected by the Ozone Monitoring Instrument, Geophys. Res. Lett., 34, L09801, doi:10.1029/2006GL029020, 2007.

Charlson, R. J., Lovelock, J. E., Andreae, M. O., andWarren, S. G., Oceanic phytoplankton, atmospheric sulphur, cloud albedo and climate, Nature, 326, 655-661, 1987.

Clarke, A. D. and Kapustin, V. N.: A pacific aerosol survey. Part I: A decade of data on particle production, transport, evolution, and mixing in the troposphere, J. Atmos. Sci., 59, 363-382, 2002.

Clarke, A. D., Eisele, F., Mauldin, R. L., Tanner, D., Litchy, M., Particle production in the remote marine atmosphere: Cloud outflow and subsidence during ACE 1, J. Geophys. Res.-Atmos., 103, 16397-16409, 1998.

Clarke, A. D., Clarke, A. D., Eisele, F., Kapustin, V. N., Moore, K., Tanner, D., Mauldin, R. L.,Litchy, M., Lienert, B., Carrol, M. A., and Albercook, G.: Nucleation in the equatorial free troposphere: Favorable environments during PEM-Tropics, J. Geophys. Res.Atmos., 104, 5735-5744, 1999.

Clegg, S. L., Rard, J. A., and Pitzer, K. S.: Thermodynamic properties of 0-6 mol kg-1 aqueous sulfuric acid from 273.15 to 328.15 K, J. Chem. Soc., Faraday Trans., 90, 1875-1894, doi:10.1039/FT9949001875, 1994.

Connolly, P. J., Choularton, T. W., Gallagher, M. W., Bower, K. N., Flynn, M. J., and Whiteway, J. A.: Cloud-resolving simulations of intense tropical Hector thunderstorms: Implications for aerosol-cloud interactions, Q. J. Roy. Meteorol. Soc., 132, 30793106, doi:10.1256/qj.05.86, 2006.

Crumeyrolle, S., Manninen, H. E., Sellegri, K., Roberts, G., Gomes, L., Kulmala, M., Weigel, R., Laj, P., and Schwarzenboeck, A.: New particle formation events measured on board the ATR-42 aircraft during the EUCAARI campaign, Atmos. Chem. Phys., 10, 6721-6735, doi:10.5194/acp-10-6721-2010, 2010.

Crutzen P. J. and Lawrence, M.: The Impact of Precipitation Scavenging on the Transport of Trace Gases: A 3-Dimensional Model Sensitivity Study, J. Atmos. Chem., 37, 81-112, 2000.

Curtius, J.: Nucleation of atmospheric aerosol particles, C. R. Physique, 7, 1027-1045, 2006.

Curtius, J., Froyd, K. D., and Lovejoy, E. R.: Cluster Ion Thermal Decomposition (I): Experimental Kinetics Study and ab Initio Calculations for HSO4-(H2SO4)x(HNO3)y, J. Phys. Chem. A, 105, 10867-10873, 2001a.

Curtius, J., Sierau, B., Arnold, F., de Reus, M., Ström, J., Scheeren, H. A., and Lelieveld, J.: Measurement of aerosol sulfuric acid 2. Pronounced layering in the free troposphere during the second Aerosol Characterization Experiment (ACE 2), J. Geophys. Res.Atmos., 106, 31975-31990, 2001b. 
Curtius, J., Weigel, R., Vössing, H.-J., Wernli, H., Werner, A., Volk, C.-M., Konopka, P., Krebsbach, M., Schiller, C., Roiger, A., Schlager, H., Dreiling, V., and Borrmann, S.: Observations of meteoric material and implications for aerosol nucleation in the winter Arctic lower stratosphere derived from in situ particle measurements, Atmos. Chem. Phys., 5, 3053-3069, doi:10.5194/acp-5-3053-2005, 2005.

Curtius, J., Lovejoy, E. R., and Froyd, K. D.: Atmospheric ioninduced aerosol nucleation, Space Sci. Rev., 125(1-4), 159-167, 2006.

Dye, J. E. and Baumgardner, D.: Evaluation of the Forward Scattering Spectrometer Probe. Part I: Electronic and optical studies, J. Atmos. Ocean. Tech., 1, 329-344, 1984.

de Reus, M., Borrmann, S., Bansemer, A., Heymsfield, A. J., Weigel, R., Schiller, C., Mitev, V., Frey, W., Kunkel, D., Kürten, A., Curtius, J., Sitnikov, N. M., Ulanovsky, A., and Ravegnani, F.: Evidence for ice particles in the tropical stratosphere from in-situ measurements, Atmos. Chem. Phys., 9, 6775-6792, doi:10.5194/acp-9-6775-2009, 2009.

Eichkorn, S., Wilhelm, S., Aufmhoff, H., Wohlfrom, K. H., and Arnold, F.: Cosmic ray-induced aerosol-formation: First observational evidence from aircraft-based ion mass spectrometer measurements in the upper troposphere, Geophys. Res. Lett., 29, 1698, doi:10.1029/2002GL015044, 2002.

Ekman, A. M. L., Wang, C., Ström, J., and Krejci, R.: Explicit Simulation of Aerosol Physics in a Cloud-Resolving Model: Aerosol Transport and Processing in the Free Troposphere, J. Atmos. Sci., 63, 682-696, 2006.

Ekman, A. M. L., Krejci, R., Engström, A., Ström, J., de Reus, M., Williams, J., and Andreae, M. O.: Do organics contribute to small particle formation in the Amazonian upper troposphere?, Geophys. Res. Lett., 35, L17810, doi:10.1029/2008GL034970, 2008.

Emanuel, K. A. and Živković-Rothman, M.: Development and evaluation of a convection scheme for use in climate models, J. Atmos. Sci., 56, 1766-1782, 1999.

English, J. M., Toon, O. B., Mills, M. J., and Yu, F.: Microphysical simulations of new particle formation in the upper troposphere and lower stratosphere, Atmos. Chem. Phys., 11, 9303-9322, doi:10.5194/acp-11-9303-2011, 2011.

Ferguson, D. J., Barnie, T. D., Pyle, D. M., Oppenheimer, C., Yirgu, G., Lewi, E., Kidane, T., Carn, S., and Hamling, I.: Recent riftrelated volcanism in Afar, Ethiopia, Earth. Planet. Sc. Lett., 292, 409-418, doi:10.1016/j.eps1.2010.02.010, 2010.

Fiebig, M., Stein, C., Schröder, F., Feldpausch, P., and Petzold, A.: Inversion of data containing information on the aerosol particle size distribution usingmultiple instruments. J. Aerosol Sci., 36, 1353-1372, 2005.

Fierli, F., Orlandi, E., Law, K. S., Cagnazzo, C., Cairo, F., Schiller, C., Borrmann, S., Di Donfrancesco, G., Ravegnani, F., and Volk, C. M.: Impact of deep convection in the tropical tropopause layer in West Africa: in-situ observations and mesoscale modelling, Atmos. Chem. Phys., 11, 201-214, doi:10.5194/acp-11201-2011, 2011.

Forster, C., Stohl, A., and Seibert, P.: Parameterization of convective transport in a Lagrangian particle dispersion model and its evaluation, J. Appl. Met. Clim., 46, 403-422, 2007.

Frey, W., Borrmann, S., Kunkel, D., Weigel, R., de Reus, M., Schlager, H., Roiger, A., Voigt, C., Hoor, P., Curtius, J., Krämer,
M., Schiller, C., Volk, C. M., Homan, C. D., Fierli, F., Di Donfrancesco, G., Ulanovsky, A., Ravegnani, F., Sitnikov, N. M., Viciani, S., D’Amato, F., Shur, G. N., Belyaev, G. V., Law, K. S., and Cairo, F.: In situ measurements of tropical cloud properties in the West African Monsoon: upper tropospheric ice clouds, Mesoscale Convective System outflow, and subvisual cirrus, Atmos. Chem. Phys., 11, 5569-5590, doi:10.5194/acp-11-55692011, 2011.

Froyd, K. D. and Lovejoy, E. R.: Experimental Thermodynamics of Cluster Ions Composed of H2SO4 and H2O. 1. Positive Ions, J. Phys. Chem. A, 107, 9800-9811, 2003a.

Froyd, K. D. and Lovejoy, E. R.: Experimental Thermodynamics of Cluster Ions Composed of $\mathrm{H} 2 \mathrm{SO} 4$ and H2O. 2. Measurements and ab Initio Structures of Negative Ions, J. Phys. Chem. A, 107, 9812-9824, 2003b.

Froyd, K. D., Murphy, D. M., Lawson, P., Baumgardner, D., and Herman, R. L.: Aerosols that form subvisible cirrus at the tropical tropopause, Atmos. Chem. Phys., 10, 209-218, doi:10.5194/acp-10-209-2010, 2010.

Fuchs, N. A.: The Mechanics of Aerosols, Macmillan, 1964.

Fueglistaler, S., Dessler, A. E., Dunkerton, T. J., Folkins, I., Fu, Q., and Mote, P. W.: Tropical Tropopause Layer, Rev. Geophys., 47, RG1004, doi:10.1029/2008RG000267, 2009.

Gettelman, A., de F. Forster, P. M., Fujiwara, M., Fu, Q., Vomel, H., Gohar, L. K., Johanson, C., and Ammerman, M.: Radiation balance of the tropical tropopause layer, J. Geophys. Res., 109, D07103, doi:10.1029/2003JD004190, 2004.

Giauque, W. F., Hornung, E. W., Kunzler, J. E., and Rubin, T. T.: The thermodynamic properties of aqueous sulfuric acid solutions and hydrates from 15 to $300 \mathrm{~K}$, Am. Chem. Soc. J., 82, 62-70, 1960.

Hamill, P., Jensen, E. J., Russell, P. B., and Bauman, J. J.: The life cycle of stratospheric aerosol particles, B. Am. Meteorol. Soc., 78, 1395-1410, 1997.

Hamling, I. J., Ayele, A., Bennati, L., Calais, E., Ebinger, C. J., Keir, D., Lewi, E., Wright, T. J., and Yirgu, G.: Geodetic observations of the ongoing Dabbahu rifting episode: new dyke intrusions in 2006 and 2007, Geophys. J. Int., 178, 989-1003, doi:10.1111/j.1365-246X.2009.04163.x, 2009.

Hanson, D. R. and Lovejoy, E. R.: Measurement of the thermodynamics of the hydrated dimer and trimer of sulfuric acid, J. Phys. Chem. A, 110, 9525-9528, doi:10.1021/jp062844w, 2006.

Heald, C. L., Jacob, D. J., Park, R. J., Russell, L. M., Huebert, B. J., Seinfeld, J. H., Liao, H., and Weber, R. J.: A large organic aerosol source in the free troposphere missing from current models, Geophys. Res. Lett., 32, L18809, doi:10.1029/2005GL023831, 2005.

Hermann, M., Heintzenberg, J., Wiedensohler, A., Zahn, A., Heinrich, G., and Brenninkmeijer, C. A. M.: Meridional distributions of aerosol particle number concentrations in the upper troposphere and lower stratosphere obtained by Civil Aircraft for Regular Investigation of the Atmosphere Based on an Instrument Container (CARIBIC) flights, J. Geophys. Res.-Atmos., 108, 4114, doi:4110.1029/2001JD001077, 2003.

Hermann, M., Adler, S., Caldow, R., Stratmann, F., and Wiedensohler, A.: Pressure-dependent efficiency of a condensation particle counter operated with FC-43 as working fluid, J. Aerosol Sci., 36, 1322-1337, 2005.

Homan, C. D., Volk, C. M., Kuhn, A. C., Werner, A., Baehr, J., Vi- 
ciani, S., Ulanovski, A., and Ravegnani, F.: Tracer measurements in the tropical tropopause layer during the AMMA/SCOUTO3 aircraft campaign, Atmos. Chem. Phys., 10, 3615-3627, doi:10.5194/acp-10-3615-2010, 2010.

Huntrieser, H., Feigl, C., Schlager, H., Schröder, F., Gerbig, C., van Velthoven, P., Flatøy, F., Théry, C., Petzold, A., Höller, H., and Schumann, U.: Airborne measurements of NOx, tracer species and small particles during the European Lightning Nitrogen Oxides Experiment, J. Geophys. Res.-Atmos., 107, 4113, doi:10.1029/2000JD000209, 2002.

Jonsson, H. H., Wilson, J. C., Brock C. A., Knollenberg, R. G., Newton, R., Dye, J. E., Baumgardner, D., Borrmann, S., Ferry, G. V., Pueschel, R., Woods, D. C., and Pitts, M. C.: Performance of a focused cavity aerosol spectrometer for measurements in the stratosphere of particle size in the 0.06-2.0 $\mu \mathrm{m}$ Diameter Range, J. Ocean. Atmos. Tech., 12, 115-129, 1995.

Kanawade, V. and Tripathi, S. N.: Evidence for the role of ion-induced particle formation during an atmospheric nucleation event observed in Tropospheric Ozone Production about the Spring Equinox (TOPSE), J. Geophys. Res., 111, D02209, doi:10.1029/2005JD006366, 2006.

Kazil, J. and Lovejoy, E. R.: Tropospheric ionization and aerosol production: A model study, J. Geophys. Res.-Atmos., 109, D19206, doi:19210.11029/12004JD004852, 2004.

Kazil, J., Lovejoy, E. R., Barth, M. C., and O'Brien, K.: Aerosol nucleation over oceans and the role of galactic cosmic rays, Atmos. Chem. Phys., 6, 4905-4924, doi:10.5194/acp-6-4905-2006, 2006.

Kazil, J., Lovejoy, E. R., Jensen, E. J., and Hanson, D. R.: Is aerosol formation in cirrus clouds possible?, Atmos. Chem. Phys., 7, 1407-1413, doi:10.5194/acp-7-1407-2007, 2007.

Kerminen, V.-M., Petäjä, T., Manninen, H. E., Paasonen, P., Nieminen, T., Sipilä, M., Junninen, H., Ehn, M., Gagn, S., Laakso, L., Riipinen, I., Vehkamäki, H., Kurten, T., Ortega, I. K., Dal Maso, M., Brus, D., Hyvärinen, A., Lihavainen, H., Leppä, J., Lehtinen, K. E. J., Mirme, A., Mirme, S., Hõrrak, U., Berndt, T., Stratmann, F., Birmili, W., Wiedensohler, A., Metzger, A., Dommen, J., Baltensperger, U., Kiendler-Scharr, A., Mentel, T. F., Wildt, J., Winkler, P. M., Wagner, P. E., Petzold, A., Minikin, A., Plass-Dülmer, C., Pöschl, U., Laaksonen, A., and Kulmala, M.: Atmospheric nucleation: highlights of the EUCAARI project and future directions, Atmos. Chem. Phys., 10, 10829-10848, doi:10.5194/acp-10-10829-2010, 2010.

Khosrawi, F. and Konopka, P.: Enhanced particle formation and growth due to mixing processes in the tropopause region, Atmos. Environ., 37, 903-910, 2003.

Kirkby, J., Curtius, J., Almeida, J., Dunne, E., Duplissy, J., Ehrhart, S., Franchin, A., Gagné, S., Ickes, L., Kürten, A., Kupc, A., Metzger, A., Riccobono, F., Rondo, L., Schobesberger, S., Tsagkogeorgas, G., Wimmer, D., Amorim, A., Bianchi, F., Breitenlechner, M., David, A., Dommen, J., Downard, A., Ehn, M., Flagan, R. C., Haider, S., Hansel, A., Hauser, D., Jud, W., Junninen, H., Kreissl, F., Kvashin, A., Laaksonen, A., Lehtipalo, K., Lima, J., Lovejoy, E. R., Makhmutov, V., Mathot, S., Mikkilä, J., Minginette, P., Mogo, S., Nieminen, T., Onnela, A., Pereira, P., Petäjä, T., Schnitzhofer, R., Seinfeld, J. H., Sipilä, M., Stozhkov, Y., Stratmann, F., Tomé, A., Vanhanen, J., Viisanen, Y., Vrtala, A., Wagner, P. E., Walther, H., Weingartner, E., Wex, H., Winkler, P. M., Carslaw, K. S., Worsnop, D. R., Baltensperger, U., and Kulmala, M.: Role of sulphuric acid, ammonia and galactic cosmic rays in atmospheric aerosol nucleation, Nature, 476, 429-433, 2011.

Konopka, P., Günther, G., Müller, R., dos Santos, F. H. S., Schiller, C., Ravegnani, F., Ulanovsky, A., Schlager, H., Volk, C. M., Viciani, S., Pan, L. L., McKenna, D.-S., and Riese, M.: Contribution of mixing to upward transport across the tropical tropopause layer (TTL), Atmos. Chem. Phys., 7, 3285-3308, doi:10.5194/acp-7-3285-2007, 2007.

Krejci, R., Ström, J., de Reus, M., Hoor, P., Williams, J., Fischer, H., and Hansson, H. C.: Evolution of aerosol properties over the rain forest in Surinam, South America, observed from aircraft during the LBA-CLAIRE 98 experiment, J. Geophys. Res.-Atmos., 108, 4561, doi:10.1029/2001JD001375, 2003.

Kulmala, M., Reissell, A., Sipilä, M., Bonn, B., Ruuskanen, T. M., Lehtinen, K. E. J., Kerminen, V.-M., and Ström, J.: Deep convective clouds as aerosol production engines: Role of insoluble organics, J. Geophys. Res., 111, D17202, doi:10.1029/2005JD006963, 2006.

Law, K. S., Fierli, F., Cairo, F., Schlager, H., Borrmann, S., Streibel, M., Real, E., Kunkel, D., Schiller, C., Ravegnani, F., Ulanovsky, A., D'Amato, F., Viciani, S., and Volk, C. M.: Air mass origins influencing TTL chemical composition over West Africa during 2006 summer monsoon, Atmos. Chem. Phys., 10, 10753-10770, doi:10.5194/acp-10-10753-2010, 2010.

Lee, S. H., Reeves, J. M. , Wilson, J. C. , Hunton, D. E., Viggiano, A. A., Miller, T. M., Ballenthin, J. O., and Lait, L. R.: Particle formation by ion nucleation in the upper troposphere and lower stratosphere, Science, 301, 1886-1889, 2003.

Lee, S. H., Wilson, J. C., Baumgardner, D., Herman, R. L., Weinstock, E. M., LaFleur, B. G., Kok, G., Anderson, B., Lawson, P., Baker, B., Strawa, A., Pittman, J. V., Reeves, J. M., and Bui, T. P.: New particle formation observed in the tropical/subtropical cirrus clouds, J. Geophys. Res.-Atmos., 109, D20209, doi:20210.21029/22004JD005033, 2004.

Lelieveld, J., Crutzen, P. J., Ramanathan, V., Andreae, M. O., Brenninkmeijer, C. A. M., Campos, T., Cass, G. R., Dickerson, R. R., Fischer, H., de Gouw, J. A., Hansel, A., Jefferson, A., Kley, D., de Laat, A. T. J., Lal, S., Lawrence, M. G., Lobert, J. M., Mayol-Bracero, O. L., Mitra, A. P., Novakov, T., Oltmans, S. J., Prather, K. A., Reiner, T., Rodhe, H., Scheeren, H. A., Sikka, D., and Williams, J.: The Indian Ocean Experiment: Widespread Air Pollution from South and Southeast Asia, Science, 291, 10311036, 2001.

Li, K.-F., Cageao, R. P., Karpilovsky, E. M., Mills, F. P., Yung, Y. L., Margolis, J. S., and Sander, S. P.: OH column abundance over Table Mountain Facility, California: AM-PM diurnal asymmetry, Geophys. Res. Lett., 32, L13813, doi:10.1029/2005GL022521, 2005.

Lovejoy, E. R. and Curtius, J.: Cluster Ion Thermal Decomposition (II): Master Equation Modeling in the Low-Pressure Limit and Fall-Off Regions. Bond Energies for HSO4-(H2SO4)x(HNO3)y, J. Phys. Chem. A, 105, 10874-10883, 2001.

Lovejoy, E. R., Curtius, J., and Froyd, K. D.: Atmospheric ioninduced nucleation of sulfuric acid and water, J. Geophys. Res.Atmos., 109, D08204, doi:08210.01029/02003JD004460, 2004.

Lucas, D. D. and Akimoto, H.: Evaluating aerosol nucleation parameterizations in a global atmospheric model, Geophys. Res. Lett., 33 L10808, doi:10810.11029/12006GL025672, 2006. 
Merikanto, J., Napari, I., Vehkamäki, H., Anttila, T., and Kulmala, M.: New parameterization of sulfuric acid-ammonia-water ternary nucleation rates at tropospheric conditions, J. Geophys. Res.-Atmos., 112, D15207, doi:10.1029/2006JD007977, 2007.

Metzger, A., Verheggen, B., Dommen, J., Duplissy, J., Prevot, A. S. H., Weingartner, E., Riipinen, I., Kulmala, M., Spracklen, D. V., Carslaw, K. S., Baltensperger, U., Evidence for the role of organics in aerosol particle formation under atmospheric conditions, P. Natl. Acad. Sci. USA , 107, 6646-6651, doi:10.1073/pnas.0911330107, 2010.

Minikin, A., Petzold, A., Ström, J., Krejci, R., Seifert,M., van Velthoven, P., Schlager, H., and Schumann, U.: Aircraft observations of the upper tropospheric fine particle aerosol in the Northern and Southern Hemispheres at midlatitudes, Geophys. Res. Lett., 30, 1503, doi:1510.1029/2002GL016458, 2003.

Mirme, S., Mirme, A., Minikin, A., Petzold, A., Hõrrak, U., Kerminen, V.-M., and Kulmala, M.: Atmospheric sub-3 nm particles at high altitudes, Atmos. Chem. Phys., 10, 437-451, doi:10.5194/acp-10-437-2010, 2010.

Murphy, D. M., Thomson, D. S., and Mahoney, M. J.: In situ measurements of organics, meteoritic material, mercury, and other elements in aerosols at 5 to 19 kilometers, Science, 282, 16641669, 1998.

Murphy, D. M., Cziczo, D. J., Froyd, K. D., Hudson, P. K., Matthew, B. M., Middlebrook, A. M., Peltier, R. E., Sullivan, A., Thomson, D. S., and Weber, R. J.: Single-particle mass spectrometry of tropospheric aerosol particles, J. Geophys. Res., 111, D23S32, doi:10.1029/2006JD007340, 2006.

O'Brien, K.: The theory of cosmic-ray and high-energy solarparticle transport in the atmosphere, The natural radiation environment VII, Proceedings of the Seventh International Symposium on the Natural Radiation Environment, Rhodes, Greece, 20-24 May, 2002, edited by: McLaughlin, J. P., Simopoulos, E. S., and Steinhäusler, F., Elsevier, 2005.

Riediger, O., Volk, C. M., Strunk, M., and Schmidt, U.: HAGAR- A new in situ tracer instrument for stratospheric balloons and high altitude aircraft, Eur. Comm. Air Pollut. Res. Report, 73, 727730, 2000.

Schumann, U.: TROCCINOX - Tropical Convection, Cirrus and Nitrogen Oxides Experiment, Overview, EGU05-A-11180, AS3.07-1MO1O-004, General Assembly 2005 of the European Geosciences Union, Vienna, Austria, 24-29 April 2005, 2005.

Schumann, U. and Huntrieser, H.: The global lightning-induced nitrogen oxides source, Atmos. Chem. Phys., 7, 3823-3907, doi:10.5194/acp-7-3823-2007, 2007.

Schiller, C., Grooß, J.-U., Konopka, P., Plöger, F., Silva dos Santos, F. H., and Spelten, N.: Hydration and dehydration at the tropical tropopause, Atmos. Chem. Phys., 9, 9647-9660, doi:10.5194/acp-9-9647-2009, 2009.

Seinfeld, J. H. and Pandis, S. N.: Atmospheric Chemistry and Physics - From Air Pollution to Climate Change (2nd edition), John Wiley \& Sons, 2006.

Shur, G. H., Sitnikov, N. M., and Drynkov, A. V.: A mesoscale structure of meteorological fields in the tropopause layer and in the lower stratosphere over the Southern tropics (Brazil), Russ. Meteorol. Hydrol., 32, 487-494, doi:10.3103/S106837390708002X, 2007.

Sokolov, L. and Lepuchov, B.: Protocol of interaction between Unit for Connection with Scientific Equipment (UCSE) and on- board scientific equipment of Geophysica aircraft (Second edition), Myasishchev Design Bureau (MDB), 1998.

Stohl, A., Wotawa, G., Seibert, P., and Kromp-Kolb, H.: Interpolation errors in wind fields as a function of spatial and temporal resolution and their impact on different types of kinematic trajectories, J. Appl. Meteor., 34, 2149-2165, 1995.

Stohl, A., Hittenberger, M., and Wotawa, G.: Validation of the Lagrangian particle dispersion model FLEXPART against large scale tracer experiments, Atmos. Environ., 32, 4245-4264, 1998.

Stohl, A., Haimberger, L., Scheele, M. P., and Wernli, H.: An intercomparison of results from three trajectory models, Meteor. Appl., 8, 127-135, 2001.

Stohl, A., Forster, C., Eckhardt, S., Spichtinger, N., Huntrieser, H., Heland, J., Schlager, H., Wilhelm, S., Arnold, F., and Cooper, O.: A backward modeling study of intercontinental pollution transport using aircraft measurements, J. Geophys. Res.-Atmos., 108, 4370, doi:10.1029/2002JD002862, 2003.

Stohl, A., Forster, C., Frank, A., Seibert, P., and Wotawa, G.: Technical note: The Lagrangian particle dispersion model FLEXPART version 6.2, Atmos. Chem. Phys., 5, 2461-2474, doi:10.5194/acp-5-2461-2005, 2005.

Stohl, A., Andrews, E., Burkhart, J. F., Forster, C., Herber, A., Hoch, S. W., Kowal, D., Lunder, C. Mefford, T. , Ogren, J. A., Sharma, S., Spichtinger, N., Stebel, K., Stone, R., Ström, J., Tørseth, K., Wehrli, C., and Yttri, K. E.: Pan-Arctic enhancements of light absorbing aerosol concentrations due to North American boreal forest fires during summer 2004, J. Geophys. Res., 111, D22214, doi:10.1029/2006JD007216, 2006.

Thomason, L., and T. Peter (Eds.): SPARC Assessment of Stratospheric Aerosol Properties, WCRP-124, WMO/TD-No. 1295, SPARC Report No. 4, Toronto, Canada, (see also: http://www. atmosp.physics.utoronto.ca/SPARC/index.html), 2006.

Thornton, D. C., Bandy, A. R., Blomquist, B. W., Bradshaw, J. D., Blake, D. R., Vertical transport of sulfur dioxide and dimethyl sulfide in deep convection and its role in new particle formation, J. Geophys. Res., 102, 28501-28509, 1997.

Twohy, C. H., Clement, C. F., Gandrud, B. W., Weinheimer, A. J., Campos, T. L., Baumgardner, D., Brune, W. H., Faloona, I., Sachse, G. W., Vay, S. A., and Tan, D.: Deep convection as a source of new particles in the midlatitude upper troposphere, J. Geophys. Res., 107, 4560, doi:10.1029/2001JD000323, 2002.

Vaughan, G., Schiller, C., MacKenzie, A. R., Bower, K., Peter, T., Schlager, H., Harris, N. R. P., and May, P. T.: SCOUTO3/ACTIVE high-altitude aircraft measurements around deep tropical convection, B. Am. Meteorol. Soc., 89, 647-662, 2008.

Vernier, J.-P., Thomason, L. W., Pommereau, J.-P., Bourassa, A., Pelon, J., Garnier, A., Hauchecorne, A., Blanot, L., Trepte, C., Degenstein, D., and Vargas, F.: Major influence of tropical volcanic eruptions on the stratospheric aerosol layer during the last decade, Geophys. Res. Lett., 38, L12807, doi:10.1029/2011GL047563, 2011.

Viciani, S., D’Amato, F., Mazzinghi, P., Castagnoli, F., Toci, G., and Werle, P. A.: A cryogenically operated laser diode spectrometer for airborne measurement of stratospheric trace gases, Appl. Phys, B., 90, 581-592, 2008.

Wang, S., Pickett, H. M., Pongetti, T. J., Cheung, R., Yung, Y. L., Shim, C., Li, Q., Canty, T., Salawitch, R. J., Jucks, K. W., Drouin, B., and Sander, S. P.: Validation of Aura Microwave Limb Sounder OH measurements with Fourier Trans- 
form Ultra-Violet Spectrometer total $\mathrm{OH}$ column measurements at Table Mountain, California, J. Geophys. Res., 113, D22301, doi:10.1029/2008JD009883, 2008.

Weber, R. J., McMurry, P. H., Eisele, F. L., and Tanner, D. J.: Measurement of Expected Nucleation Precursor Species and 3-500Nm Diameter Particles at Mauna-Loa-Observatory, Hawaii, J. Atmos. Sci., 52, 2242-2257, 1995.

Weber, R. J., McMurry, P. H., Mauldin, R. L., Tanner, D. J., Eisele, F. L., Clarke, A. D., and Kapustin, V. N.: New particle formation in the remote troposphere: A comparison of observations at various sites, Geophys. Res. Lett., 26, 307-310, 1999.

Weinzierl, B., Petzold, A., Esselborn, M., Wirth, M., Rasp, K., Kandler, K., Schütz, L., Koepke, P., and Fiebig, M.: Airborne measurements of dust layer properties, particle size distribution and mixing state of Saharan dust during SAMUM 2006, Tellus, 61B, 96-117, doi:10.1111/j.1600-0889.2008.00392.x, 2009.

Weigel, R., Hermann, M., Curtius, J., Voigt, C., Walter, S., Bttger, T., Lepukhov, B., Belyaev, G., and Borrmann, S.: Experimental characterization of the COndensation PArticle counting System for high altitude aircraft-borne application, Atmos. Meas. Tech., 2, 243-258, doi:10.5194/amt-2-243-2009, 2009.

Wilson, J. C., Jonsson, H. H., Brock, C. A., Toohey, D. W., Avalone, L. M., Baumgardner, D., Dye, J. E., Poole, L. R., Woods, D. C., DeCoursey, R. J., Osborne, M., Pitts, M. C., Kelly, K. K., Chan, K. R., Ferry, G. V., Loewenstein, M., Podolske, J. R., and Weaver, S.: In situ observations of aerosol and chlorine monoxide after the 1991 eruption of Mount Pinatubo: effect of reactions on sulfate aerosol, Science, 261, 1140-1143, 1993.
Wilson, J. C., Lee, S.-H., Reeves, J. M., Brock, C. A., Jonsson, H. H., Lafleur, B. G., Loewenstein, M., Podolske, J., Atlas, E., Boering, K., Toon, G., Fahey, D., Bui, T. P., Diskin, G., and Moore, F.: Steady-state aerosol distributions in the extra-tropical, lower stratosphere and the processes that maintain them, Atmos. Chem. Phys., 8, 6617-6626, doi:10.5194/acp-8-6617-2008, 2008.

Yu, F. Q. and Turco, R. P.: From molecular clusters to nanoparticles: Role of ambient ionization in tropospheric aerosol formation, J. Geophys. Res.-Atmos., 106, 4797-4814, 2001.

Yu, F., Luo, G., Bates, T. S., Anderson, B., Clarke, A., Kapustin, V., Yantosca, R. M., Wang, Y., and Wu, S.: Spatial distributions of particle number concentrations in the global troposphere: Simulations, observations, and implications for nucleation mechanisms, J. Geophys. Res., 115, D17205, doi:10.1029/2009JD013473, 2010.

Zhang, R. Y., Suh, I. Zhao, J., Zhang, D., Fortner, E. C., Tie, X., Molina, L. T., and Molina, M. J.: Atmospheric new particle formation enhanced by organic acids, Science, 304, 1487-1490, 2004.

Zhang, Y., McMurry, P. H., Yu, F., and Jacobson, M. Z.: A comparative study of nucleation parameterizations: 1 . Examination and evaluation of the formulations, J. Geophys. Res., 115, D20212, doi:10.1029/2010JD014150, 2010. 